Cómo citar este trabajo: Rullan, O., \& Vives-Miró, S. (2020). The Catalonia/Spain conflict: a review from Geography. Boletín de la Asociación de Geógrafos Españoles, 84, 2755, 1-37. https://doi.org/10.21138/bage.2755

\title{
El conflicto Cataluña/España: una revisión desde la Geografía
}

The Catalonia/Spain conflict: a review from Geography

\author{
Onofre Rullan \\ orullan@uib.es \\ Sònia Vives-Miró \\ so.vives@gmail.com \\ Departamento de Geografía \\ Universitat de les Illes Balears (España)
}

\section{Resumen}

El trabajo analiza, en perspectiva geohistórica, las relaciones entre los gobiernos de Cataluña y el Estado español a partir de los antecedentes previos a la conformación del Estado-nación. Se analiza, en primer lugar, la literatura geográfica que ha abordado el tema para, posteriormente, recorrer la evolución de los conflictos y colaboraciones entre los nacionalismos español y catalán. Se hace un primer repaso de la colaboración España-Cataluña hasta el fin del imperio colonial (1892), momento a partir del cual las respectivas estrategias empiezan a divergir culminando en la centralización franquista (1939-1978). El Estado de las autonomías supone un paréntesis en el litigio que, de nuevo, se agudiza con la suspensión temporal de la autonomía catalana en aplicación del artículo 155 de la Constitución. Se concluye que, desde la geografía académica española, se ha analizado la organización interna del Estado, pero no una posible organización territorial con alteración de las fronteras exteriores del actual Estado. En segundo lugar que, en referencia al conflicto, sólo se vislumbran posibles soluciones en contextos de confederación. Y, 
en tercer lugar, que en el actual momento de globalización postmoderna, el litigio no puede entenderse en los términos clásicos de enfrentamiento centro político/periferia económica.

Palabras clave: Cataluña; España; independentismo; nacionalismo; organización territorial.

\begin{abstract}
The present work analyses the relations between the governments of Catalonia and the Spanish state through the antecedents leading up to the conformation of the current nation-state. First, the geographic literature that has addressed the subject is analysed in order to subsequently discuss the evolution of the relations between Spanish and Catalan nationalisms. A review of SpanishCatalan collaboration through the end of the colonial empire is carried out, as at that point in time respective strategies began to diverge, culminating in Franco's centralization. In 2017, the Spanish state again intervened in Catalonia with the temporary suspension of Catalan autonomy via the application of article 155 of the Spanish Constitution. This work is based on geohistorical sources and comparative analyses of the different discourses. It is concluded that the internal organization of the state has been analysed considering academic Spanish geography, but no special attention has been given to analysing possible territorial organization that could lead to an alteration of the state's external borders; that those making reference to the conflict only envision possible solutions in contexts of confederation; and that in the context of postmodernism, the dispute cannot be understood in the classical terms of the political centre/economic periphery conflict.
\end{abstract}

Key words: Catalonia; Spain; independence; nationalism; territorial organization.

En Europa el nacionalismo es vilipendiado al tiempo que se practica. (Smith, 1976, p. 33)

La geografia ha estat sovint directament involucrada en l'argumentació legitimadora de projectes ideològics de caràcter nacionalista.

(Nogué, 1993, p. 193)

\title{
1 Introducción
}

Procés, proceso, es el término que más aparece en los discursos que acompañan el conflicto político que, desde la sentencia del Tribunal Constitucional de 2010, enfrenta a una parte significativa de la población y políticos de las instituciones catalanas con una parte, no menos significativa, de población y políticos de las instituciones del resto de España. Pero todo proceso, 
si realmente lo es, no está acotado a específicas fechas de inicio y final. Los procesos, evolucionando a lo largo de periodos que pueden ser muy dilatados, anclan sus raíces en el pasado y proyectan sus inercias hacia el futuro.

Esta idea diacrónica -dinámica y mutante- de todo proceso puede servir para ordenar las cuestiones relativas al conflicto España-Cataluña. La prehistoria del proceso catalán surge en paralelo y como reacción a políticas homogeneizadoras que anclan sus raíces, como mínimo, en el siglo XVIII y que culminan en el franquismo. A la dura dictadura le sigue un período de explosión de diversidad, como habitualmente aflora tras los cataclismos sistémicos -como fue la muerte del dictador y su régimen-. Esta fase de diversidad se inauguró con la restauración de la Generalitat en 1977, antes de la aprobación de la Constitución de 1978, y con la intervención de la Generalitat a través de la aplicación del artículo 155 de la carta magna -entre el 27 de octubre de 2017 y el 2 de junio de 2018- se abre un nuevo período repleto de incógnitas. La intervención de la Generalitat, desde posiciones contrarias al proceso, se considera como el necesario "regreso del Estado a Cataluña" después de una supuesta dejadez constitucional postfranquista, mientras que desde el independentismo es considerado como el último de los bombardeos, ahora incruento, a que regularmente se somete a Cataluña cada 50 años. ${ }^{1}$

\section{El conflicto visto y analizado desde la geografía académica española}

Las reflexiones sobre la organización territorial del Estado español desde la geografía académica española han sido tildadas por algunos autores de escasas (García, 2002, p. 667; Gómez, 2013, p. 20). Un desierto en el debate del que, durante mucho tiempo, sólo se escapó la celebración de las jornadas organizadas en Valladolid por la Asociación de Geógrafos Españoles en diciembre de 1979, posteriormente publicadas en forma de libro (AGE, 1980), el encuentro de geografía regional celebrado en Gerona en 1989 y el número especial del Boletín de la Asociación de Geógrafos Españoles publicado en 2001.

En las jornadas de 1979 se debatió, en cuatro ponencias, sobre el concepto de región, división regional, regionalización de España y desequilibrios regionales. Pero las aportaciones y debates

1 La frase se debe al general liberal Espartero tras bombardear Barcelona en respuesta a la revuelta de la Jamància de 1842. La derrota catalana en la Guerra dels Segadors de mediados del siglo XVII supone el primero de estos bombardeos con el deseo explícito del Conde Duque de Olivares de "allanar Cataluña". La derrota y ocupación borbónica de 1714 es el segundo bombardeo. El tercero es el ya citado de Espartero de 1842 al que siguió el del General Prim un año después. El cuarto se llevó a cabo contra las barricadas de los insurgentes contra las quintas de la guerra de Marruecos durante la Semana Trágica (1909). El quinto es el bombardeo franquista antes de entrar militarmente en Barcelona en 1939. 
sobre la nueva organización territorial que en aquellos momentos se estaba gestando ya estaba llegando tarde. Las jornadas se celebraron los días 17 y 18 de diciembre de 1979 coincidiendo exactamente con la publicación en el BOE de los estatutos vasco y catalán (Leyes Orgánicas 3/1979 y 4/1979 de 18 de diciembre). El proceso de formación del actual mapa autonómico ya estaba lanzado y prácticamente decidido y concluiría cuatro años más tarde (1983) con la aprobación de los estatutos de Extremadura, Baleares, Madrid y Castilla-León. Las jornadas se celebraron por tanto justo en el Big Bang del estado de las autonomías y sorprende que apenas se incidiera en la misma conformación del mapa que se estaba proponiendo, ni en el contenido sustantivo de las administraciones autonómicas que se estaban fundando. Algunos de los ponentes llegaron incluso a afirmar que

Aquí no hemos venido a hacer política sino geografía (Casas, 1980, p. 164).

Una frase que conecta con otras posteriores enunciadas desde la geografía académica española al debatir sobre la conveniencia o no de considerar la validez de las llamadas regiones históricas:

Lo científico, llamémosle así, estaba muy por encima de lo político, siempre contingente (García Fernández, 2000, p. 8).

Y ahí radica seguramente parte de la posición de marginalidad del punto de vista geográfico con respeto a un tema tan clave como el que nos ocupa. Al no debatir políticamente no se entró en un tema que es completamente político. El posicionamiento como observadores supuestamente asépticos y neutrales a los que en ocasiones nos tiene acostumbrado determinado tipo de discursos, excluye al observador de la toma de decisiones y, a medio plazo, debilita la disciplina. En este sentido, se huía y se alejaba a la geografía académica española de los posicionamientos lefebvrianos defensores de la idea de que en el proceso de producción del espacio hay una inherente dimensión política que lleva a diferentes formas de control sobre el mismo (Lefebvre, 1976; Corrêa, 1995).

Posteriormente a la celebración (1979) y publicación (1980) de las jornadas de Valladolid se llevaron a cabo otras iniciativas focalizadas en la problemática regional. En julio de 1989 el Estudi General de Gerona organizó un curso de verano sobre geografía regional por la presencia internacional de nombres como Doreen Massey y Peter J. Taylor. Las actas del encuentro se publicaron al año siguiente en un número monográfico de Treballs de la Societat Catalana de Geografia $^{2}$. En la misma línea, once años después del encuentro de Gerona y veintiún después 
de la reunión de Valladolid, el número 32 (2001) del Boletín de la Asociación de Geógrafos Españoles se dedicó monográficamente a "Región y geografía regional" 3 . Tanto los trabajos presentados en los encuentros de Valladolid y Gerona como el número 32 del Boletín de la Asociación de Geógrafos Españoles se focalizaron mayoritariamente en la ontología de la región, no tanto en la del Estado. La demarcación, jurisdicción y alcance del Estado, hasta tiempos relativamente recientes, apenas se ha discutido y/o cuestionado, sólo las delimitaciones de sus regiones internas y muy tímidamente sus competencias. En el fondo subyace la idea de que el ente político-administrativo que llamamos Estado no puede ser tratado como tratamos a las regiones a las que les podemos discutir sus límites y justificaciones. En consecuencia, apenas se debate sobre la conveniencia o no de ampliar las fronteras del Estado español (iberismo desfronterizador) o reducirlas (independentismo refronterizador). La potencia del argumentario del Estado-nación parece que ha aparcado cualquier debate sobre sus límites.

Aun así, con una periodicidad más o menos regular, como hemos anotado, se ha celebrado algún tipo de evento para reflexionar sobre la región y la organización territorial: Valladolid 1979, Gerona, 1989, monográfico del BAGE (2001). Pero en la década de 2010, espoleados por el conflicto España-Cataluña, los encuentros se han sucedido. En 2013, se celebró un encuentro en Toledo de similar temática (Gómez, Lois, \& Nel.lo, 2013), un encuentro que tendría una renovada edición en abril de $2018^{4}$. Dos meses más tarde (junio de 2018), de nuevo con el tema catalán flotando en el ambiente, el grupo de trabajo de Historia del Pensamiento Geográfico de la AGE organizó su IX coloquio en Concentaina que ha dado lugar a otra publicación (Farinós, Ojeda \& Trillo, 2019). Finalmente, el XXVI congreso de la AGE, a celebrar en octubre de 2019, ha incluido una línea temática sobre la organización territorial del Estado.

Algunos tópicos son algo recurrentes en todos estos encuentros: la supuesta vinculación de la crisis territorial con la económica, ${ }^{5}$ la Geografía tiene mucho que decir en cuanto a la organización

3 Ver https://www.age-geografia.es/ojs/index.php/bage/issue/view/46 Antes de la publicación del número 32 del Boletín de la Asociación de Geógrafos Españoles ya habían aparecido diferentes trabajos sobre el tema regional que pueden consultarse en la presentación del referido número 32 (Rodríguez \& Plaza, 2001).

4 El encuentro se celebró en Barcelona y las presentaciones pueden consultarse en la sección de "Debates de Actualidad", abierta en la Web de la AGE, que lleva por título "Grupo de Toledo. Modelo Territorial" https://www.age-geografia.es/site/modelo-territorial/ En este enlace, además, se pueden encontrar varias aportaciones sobre el tema prevenientes de muy distintas disciplinas.

5 Algunos estudios más específicos han demostrado claramente la vinculación entre crisis urbana y conflicto catalán (Nel.lo \& Gomà, 2018). 
territorial ${ }^{6}$ y, sobre todo, cierta confusión entre organización político-administrativa propia de la Geografía Política y modelo territorial objeto de la Ordenación de Territorio (Zoido, 2019), cuando Organización y Ordenación del Territorio no son expresiones intercambiables. El conflicto EspañaCataluña no ha aflorado solamente por cuestiones como la radialidad de la red de vías terrestres, la no ejecución del corredor mediterráneo o la discusión sobre los vuelos intercontinentales del aeropuerto de Barcelona - que también-, sino por la disputa sobre la soberanía y disponibilidad del dinero público o la gestión de temas identitarios como la lengua. En definitiva remite a la coexistencia en el interior de España, de comunidades políticas que, como Cataluña y el País Vasco, se consideran naciones.

Jacobo García, ha hecho notar que, desde la Geografía, son pocas las aportaciones sobre el debate en torno a la organización territorial interna del Estado ${ }^{7}$ a diferencia de otras disciplinas incorporadas al debate algunas décadas antes como la Economía, la Historia, la Sociología o la Antropología (García, 2002, p. 400-401). Algunos autores (García, 2002, p. 667-675; Gómez, 2019, p. 29) han imputado la escasa presencia de la Geografía a la hora de la conformación del actual mapa autonómico (1979-1983) al alejamiento de la geopolítica (no exclusivo del caso español) y a la focalización de nuestros estudios en las escalas comarcales y locales con un marcado sesgo descriptivo (Lois, 2013, p. 64). Aun así, parece que ha sido decisiva la influencia de las distintas geografías de España anteriores a la Constitución de 1978 en los agrupamientos provinciales preautonómicos (García, 2000), que darían lugar a la conformación del actual mapa autonómico. Un mapa que han legitimado muchos trabajos de la geografía académica a partir de 1983. La adecuación del índice en 1987 (5a edición) de la Geografía Regional de España al mapa autonómico (García, 2002, p. 670-671) o la misma edición de una geografía regional de España con el título de La España de las Autonomías (García \& Sotelo, 1999) son un buen ejemplo de la legitimación a posteriori del mapa que ha implicado un manifiesto apriorismo en ningún cuestionado (Burgueño, 2002, p. 173).

Algunas tesis, eso sí, se han centrado en el análisis de la organización territorial interna del estado, especialmente dos. Una analizando la conformación y vigencia de la división provincial (Burgueño, 1996). La otra, ya citada, amplió el análisis al mapa autonómico en lo que es, por el momento, el

6 La verdad es que los geógrafos leemos mucho fuera de nuestras fronteras (Plaza, 2013b, p. 162). Un análisis bibliográfico de la publicación del encuentro de Toledo así lo atestigua. Tan solo un $37.5 \%$ de las referencias provienen del campo de la geografía, un porcentaje que desciende al 30.8 si eliminamos las autocitas, lo cual puede leerse en clave de interdisciplinariedad o de una cierta dejación del tema por parte de la geografía (Gómez, 2013, p. 20-21).

7 Para una visión de síntesis véase Plaza (2016). 
estudio más completo sobre la conformación de dicho mapa hecho desde la Geografía (García, 2002). ${ }^{8}$

En cualquier caso lo que ha sido prácticamente nulo, tanto desde la Geografía como desde otras disciplinas, han sido los trabajos que hayan cuestionado las fronteras exteriores del Estado como sí lo han hecho con los límites de las regiones internas. ${ }^{9}$ El Estado-nación español -y por tanto sus fronteras- se ha asumido como si de un TINA (There Is No Alternative) se tratara y lo que ahora se discute en el conflicto Cataluña/España es la soberanía del Estado y, consecuentemente, las fronteras exteriores, no su organización interna.

De hecho, lo que ha sucedido con el no cuestionamiento del Estado-nación español ha sido su legitimación por defecto. Al centrar los debates en la ontología de la región y en la organización territorial interna se estaba, consciente o inconscientemente, dando por hecho que el Estado y sus fronteras exteriores -la soberanía- eran y son inalterables. Han sido prácticamente nulos los planteamientos evolutivos del Estado que pudieran cuestionar la coropleta España. Taylor, hace años, hizo una interesante observación en referencia a las regiones que vale también para los Estados:

Tradicionalmente (...), los geógrafos han tratado sus regiones como si fueran eternas, en un paradigma environamentalista. ¿Por qué empezar con la "base física», continuar por la localización de la agricultura y acabar con la industria y las ciudades, tal como la mayoría de manuales regionales hacen? Lo que nosotros proponemos aquí es una construcción social que no tiene nada de eterna: las regiones históricas. En esta teoría las regiones son creadas, se reproducen y, finalmente, desaparecen

8 Este extenso y muy elaborado trabajo es de enfoque más "cortesano" que periférico. Se trata de un excelente trabajo que sin embargo no cita, por ejemplo, las tres obras prístinas de reivindicación territorial/nacional planteadas desde los tres territorios del área lingüística catalana en pleno franquismo (Vicens, 1954; Fuster, 1962; Melià, 1967). El último de estos trabajos seria reelaborado (Melià, 1977) al desaparecer el control previa de la censura.

9 Basta analizar los congresos de la AGE para comprobar que, entre 1991 y 2011, tan solo el 3,4 \% de las comunicaciones trataron de la "Articulación y estructura del territorio" y aun en estas comunicaciones los temas abordados son los referidos a comercialización, infraestructuras portuarias y espacios de concentración de actividad económica inducidos por infraestructuras de transporte como el TAV (Plaza, 2013ª p. 295). Las actividades del grupo de Estudios Regionales de la AGE tampoco ha incidido en el tema (Contreras, 2013). Mientras redactábamos estas líneas hemos podido comprobar como la línea temática "Organización territorial del Estado: aportes desde la geografía" (LT3.1) a desarrollar en el ya citado XXVI Congreso de la AGE a celebrar en Valencia (22-25/10/2019) es la que ha recibido menos comunicaciones de las 12 líneas temáticas que componen el congreso, en concreto 9 de las 270 aportaciones lo que tan solo supone un 3,3\% del total (https://congresos.adeituv.es/XXVIAGE-Valencia2019/paginas/pagina_518_9.es.html). 
de la escena mundial. Son, pues, fenómenos espacio-temporales que, del mismo modo que suelen ser presentadas espacialmente en mapas, también deben ser entendidas a través de una proyección temporal. (Taylor, 1989, p. 91).

Ese planteamiento niega las demarcaciones eternas, tanto las subestatales como las de los propios estados. En el caso español la contingencia de las demarcaciones subestatales apenas es discutida (Burgueño, 1996; García, ,2002) o, en todo caso, se ha reducido la discusión a la conveniencia de delimitar interiormente es Estado por regiones naturales o históricas (Gómez, 2018). Por el contrario, la demarcación del propio Estado español apenas ha sido cuestionada, cuando la frontera actual data de 1976, dos años antes de la constitución del $78^{10}$.

De la misma forma que los mapas presentados por los tratados de geografía de España han ayudado a consolidar y legitimar el mapa de Comunidades Autónomas, este mismo proceso de legitimación ha operado sobre el mismo mapa del Estado-nación español que, como hemos comentado, en su configuración actual, data de 1976. La Geografía Histórica, la Geopolítica, la Geografía Cultural o la Geografía Económica -las tres primeras muy poco trabajadas desde la geografía española- apenas han entrado en el tema, si es que lo han hecho. Como se ha apuntado

España es un territorio geográfico sometido a permanentes debates políticos y definido por la diversidad cultural, lingüística, donde la Geografía política y la Geografía cultural se cultivan poco, y poseen una relevancia menor en los planes de estudios universitarios (Canosa, Claval \& Lois, 2019, p. 23).

En los últimos años han aparecido algunos manuales que pueden marcar un cambio de tendencia con respeto al relato que acabamos de exponer. Así, la Geografía de España de Ariel (Gil \& Gómez, 2001) ya incorpora la parte tercera del manual con el título de El Estado español. De esquema específicamente regional es el manual publicado por la Universidad de Valencia (Farinós, 2002) que dedica un capítulo, el 2, a la organización del territorio español. Especialmente destacable son las publicaciones, también desde Valencia, de Joan Romero entre

10 Las fronteras del Estado o, si se quiere, del alcance territorial de las diferentes dinastías monárquicas, han experimentado importantes variaciones a lo largo de los siglos fruto de tratados internacionales sin contar con los efectos de diferentes guerras de independencia como la de los Países Bajos o de las colonias americanas. Bajo el reinado de Felipe IV, en 1640, se independiza Portugal y, en1659, se cede el Rosellón (Cataluña del Norte) a Francia; Felipe $V$, en 1713, cede Gibraltar a Inglaterra; en 1898, durante el reinado de Alfonso XIII y bajo la regencia de $M^{a}$ Cristina, logran la independencia Cuba, Puerto Rico y Filipinas; en 1969, bajo la dictadura de Franco, se independentiza la Guinea española; por último, en 1976, ya bajo el reinado de Juan Carlos I, el mapa político de España se configura con sus actuales fronteras exteriores con la cesión a Marruecos de la antigua provincia española del Sáhara. 
las que cabe destacar una de ellas específicamente dedicada a la geopolítica española (Romero, 2009) y otra que el mismo autor coordina sobre Geografía Humana de España en la que se dedica el capítulo 2 al contexto geopolítico (Romero \& Boira, 2017).

\section{Antecedentes y evolución del conflicto}

La evolución geohistórica reciente del conflicto puede sintetizarse a partir de dos grandes fases por lo que atañe a las relaciones políticas Cataluña/España: 1) hasta la Constitución de 1978 y 2) de la aprobación de la carta magna a la aplicación de su artículo 155 a Cataluña (2017). Sin embargo vale la penar bosquejar algunos episodios anteriores.

\subsection{De la diversidad a la homogenización hasta 1978}

Con la conquista cristiana de la península lbérica y de las islas Baleares una potente tríada norteña reemplazó a la musulmana a medida que avanzaba hacia el sur: el feudalismo como sistema socioeconómico, el cristianismo como religión y las distintas lenguas románicas como idiomas. Una conquista de contexto geográfico más amplio vinculada a la expansión feudal europea en la que, entre otros, el mundo germánico desplaza a los eslavos y el inglés a gaélicos e irlandeses.

En cuanto a la geografía del avance de las lenguas románicas hacia el sur, resulta interesante constatar las diferencias entre los grupos que establecen los lingüistas. Por un lado, describen las homogeneidades entre las llamadas lenguas íbero-romances o ibero-románicas (aragonés, castellano, asturleonés y gallegoportugués) y las occitano-románicas (occitano y catalán). Estas últimas en ocasiones son descritas como subgrupo de un conjunto más amplio, las galo-románicas que incluye todas las hablas de la antigua Galia romana (Corbera, 2013, p. 35-61). Mientras las lenguas íbero-romanas evolucionaron y se difundieron a partir de focos cantábricos, y por tanto ibéricos, tanto el occitano como el catalán resultan de un impulso inicial franco. De ahí una primera gran diferencia cultural de la península Ibérica. Mientras los musulmanes unificaron culturalmente el territorio a partir de un solo foco emisor proveniente del sur, los cristianos lo hicieron, por un lado, a partir de focos cantábricos y, por otro, desde el mundo carolingio. Como apuntan los historiadores, los condes catalanes de la Marca Hispánica estaban sometidos al rey o emperador franco y, por tanto, el símbolo equivalente a Don Pelayo, como mínimo en el área lingüística catalana, lo juega Carlomagno (Furió, 2015, p. 86 y 94). Este factor condujo a diferenciar entre el feudalismo castellano con lo que el llamado "hecho diferencial catalán" ancla parte de sus raíces en esta primitiva dicotomía cantábrico-carolingia. 
En cualquier caso, las lenguas y culturas románico-cristianas, avanzando en paralelo en dirección sur, conformaban identidades de pertenencia diversificadas. Como señaló en 1973 Américo Castro:

Los habitantes de los reinos cristianos de la Península antes de fines del siglo XIII se llamaban a sí mismos, asturianos, gallegos, navarros, castellanos, leoneses, aragoneses, catalanes, etc. Pero no españoles. El único gentilicio común que reconocían y los abarcaba a todos era el de cristianos, lo que diferenciaba a asturianos, gallegos, navarros, etc. de los musulmanes de al-Andalus no era (...) el sentirse hispanos (que era el nombre aplicado al conjunto de los habitantes peninsulares, incluidos musulmanes y judíos), sino la religión (citado por García, 2002, p. 159).

Los territorios medievales, como los imperios de la antigüedad, formaban comunidades imaginarias integradas mediante una ideología religiosa (Taylor \& Flint, 2002, p. 244). Hasta tal punto era así que el topónimo España, para los primeros reinos cristianos, seguía siendo sinónimo de península Ibérica que, en los primeros momentos de la conquista, era un territorio mayoritariamente enemigo (Furió, 2015, p. 81). De hecho en la Edad Media era la religión el principal vector unificador de los territorios, como mínimo hasta la irrupción del nacionalismo que, en España, eclosionará con la guerra de la Independencia y se codificará en las Cortes de Cádiz de 1812 (Álvarez, 2001). ${ }^{11}$

El reemplazo de la religión por la nación como elemento unificador y cohesionador hará que los grandes enfrentamientos bélicos, paulatinamente, pasen de guerras de religión a guerras entre naciones:

La medida del cambio [de nación por religión] era la normalidad con que se tomaba que protestantes alemanes lucharan contra protestantes ingleses y que católicos alemanes lucharan contra católicos franceses. La religión había dejado de ser el eje

11 Entre la unión dinástica de 1469 y las Cortes de Cádiz de 1812 que proclaman la Nación española, además de la Corona, hay otra institución de carácter político-religioso común a todos los territorios, la Inquisición que se independiza de los Estados Pontificios y se pone al servicio directo de los Reyes Católicos. Se implanta en 1478, nueve años después de la unión dinástica y se abole definitivamente en 1820, después de varios vaivenes entre, por un lado, Napoleón Bonaparte y liberales y, por otro, las políticas conservadoras de Fernando VII. En el caso de la Corona de Aragón la Inquisición española data de 1482 excepto en el Reino de Mallorca que lo hace en 1488. Una de las primeras acciones de la Inquisición en la Corona de Aragón fue la simbólica quema de la llamada Biblia valenciana, primera redactada en catalán y cuarta impresa en todo el mundo. 
de las comunidades imaginarias, y la nación la había desplazado en su papel cultural (Taylor \& Flint, 2002, p. 244).

Desde el punto de vista económico los cuatro siglos que discurren entre la primera llegada de la Corona de Castilla a América (1492) y el final del Imperio español (1898) desvían gran parte del interés comercial del Mediterráneo -que gestionaba la Corona de Aragón- al Atlántico. La no participación de la Corona de Aragón en la conquista y explotación colonial de América, a diferencia de Castilla y Portugal, tendrá importantes consecuencias de cara a la organización política de la península Ibérica. Un hecho que Paul Elliot ha vinculado al colapso de la banca barcelonesa de la década de 1380 que aprovechó el capital genovés para desplazar al catalán y que, mientras agenciaba el comercio lanero castellano, pudo activar el negocio de América:

Si hubieran sido los catalanes en vez de los genoveses quienes hubieran ganado la lucha por introducirse en el sistema comercial castellano, la historia de una España unida habría tomado un giro profundamente diferente (citado por Arrighi, 1999, p. 144).

Si bien fue muy variante la importancia del comercio castellano y portugués con América a lo largo de los siglos, la verdad es que contribuyó decisivamente a la hegemonía del Imperio hispano, especialmente durante el siglo XVII, el Siglo de Oro. La centuria de máximo esplendor imperial y, por extensión, de la lengua y cultura castellana que, grosso modo, coincide con la llamada Decadència catalana. A la inicial diglosia del Siglo de Oro se le superpuso un lento proceso de sustitución lingüística a favor del castellano que se consolidó con las políticas impuestas a partir del siglo XVIII tras la victoria borbónica en la Guerra de Sucesión. Estas políticas fueron tanto implícitas (nuevos funcionarios, jueces, notarios $\square$ castellanoparlantes) como explícitas (Real célula de Carlos III de 1768 que imponía el castellano en la escuela y la administración). Unas políticas que se desplegaron sobre una sociedad que, en el XVIII, aún era mayoritariamente monolingüe con el catalán como única lengua, aunque en el XIX avanzó la bilingualización y, más lentamente, la sustitución lingüística. La Renaixença, en consonancia con el emergente romanticismo y paralela al Rexurdimento gallego (Lois, 2013, p. 72) y al Risorgimento italiano, intentó hacer frente a esta situación y reorientar la situación a favor del catalán.

Sin embargo, la unificación política borbónica que proclamaron los decretos de Nueva Planta de principios del siglo XVIII, al tiempo que radializaron la red de carreteras (Bel, 2010, p. 85-162) e incrementaron la presión del castellano sobre el catalán, abrieron oportunidades comerciales con América a los puertos de la antigua Corona de Aragón (García, 2002, p. 169). Gracias a los 
decretos de Carlos III de 1765, 1768 y especialmente el de 1778 (Reglamento y Aranceles Reales para el Comercio Libre de España a Indias) que acababa con el monopolio del puerto de Cádiz. Con ello, a partir del XVIII y especialmente durante el XIX, el comercio catalán se abrió a América y los comerciantes catalanes vieron oportunidades en la colaboración con el Estado que, hasta entonces, les eran vetadas. Una colaboración comercial con el Estado que se incrementó con la industrialización catalana de la segunda mitad del siglo XIX gracias, entre otros, al flujo de capitales que proporcionó a Cataluña el comercio con América desde 1778. Se podía comerciar con América y el emergente Estado-nación español, a instancia de la burguesía catalana, ponía protecciones arancelarias en favor de su industria. Jaume Font lo ha destacado con claridad:

la burguesía industrial sólo pedía orden y leyes proteccionistas que le garantizaran el mercado español, dejando el control el aparato del Estado en manos de la aristocracia funcionarial (Font, 2013, p. 39).

Esta fase se ha calificado de regionalismo subordinado a la identidad española -o de fusión del catalanismo con el españolismo- en ella la incipiente reivindicación de catalanidad buscaba el prestigio industrial frente al mundo al mismo tiempo que perseguía la instrumentalización del Estado a su favor para erigirse como principal motor (industrial) del progreso de España. Pierre Vilar ha datado esta etapa entre 1820 y 1885 (memorial de greuges) y lo ha llamado de regionalismo-proteccionista (Vilar, 1966, I, p. 67). Ni que decir tiene que la cuestión lingüística de esta época estaba subordinada al objetivo más general apuntado y las reivindicaciones no pasaban de planteamientos más o menos folclóricos.

La cuestión que resulta relevante esclarecer es en qué momento y circunstancias el catalanismo empieza a distanciarse del españolismo, entendidos ambos términos en función de la principal referencia ideológica y territorial a la que se van adscribiendo las élites. Tanto Pierre Vilar (1966, I, p. 65) como José Álvarez Junco han sugerido el declive del Imperio hispano como punto de inicio del progresivo y lento divorcio (Álvarez, 2018). ${ }^{12}$ Pero todavía en 1898, el poeta Joan Maragall (1860-1911), escribe su Oda a Espanya en la que, reivindicando la catalanidad y la lengua y amenazando con un Adéu, Espanya, sigue planteando las relaciones España-Cataluña en términos paterno-filiales: Escolta España, la veu d'un fill.

12 Las similitudes entre la bandera cubana y la estelada corrobora esta relación. Aunque la estelada data de algunos años posteriores al 1898, es conocida la vinculación estética y política entre ambas enseñas que nacen en el momento del finiquito del Imperio español. 
Giovanni Arrighi (1999), ha demostrado que las diferentes hegemonías mundiales se han consolidado en los momentos en que el Estado, asumiendo los costes de protección y fomento de la actividad económica, ha colaborado coordinadamente y favorecido directamente los intereses de las agencias capitalistas. A contrario sensu puede defenderse que cuando, por las razones que sea, se rompe esta colaboración, los intereses de las élites (o de algunas de ellas) y los del Estado empiezan a distanciarse. Un proceso que empezó a cuajarse en torno a las relaciones CataluñaEspaña en el tránsito del siglo XIX al XX y el nacionalismo catalán, después del llamado "desastre" de 1898, empezó poco a poco a cuestionar al anterior regionalismo de resonancia todavía claramente español. Pierre Vilar llamó a esta etapa de nacionalismo burgués en la que

una clase aspira a disponer de un Estado, y viéndose refutada por el Estado español, se repliega (...) sobre la existencia de una organización regional políticamente autónoma (Vilar, 1966, I, p. 63., traducción propia).

De hecho, el primer tercio del siglo XX registra los primeros choques políticos e intelectuales entre ambos planteamientos y, al tiempo que en Cataluña se reivindica la catalanidad, en Castilla se elabora el discurso español más meseteño. Este último se construirá fundamentalmente en base a la descripción de la Meseta Central y a la reivindicación de Castilla como elemento aglutinador del conjunto peninsular. La Meseta, que había sido descrita a principios del siglo XIX y definida como estructural a medianos del mismo siglo (Casals, 2001) se consolidará conceptualmente de forma definitiva a partir de la obra de los geólogos Macpherson y Calderón. Este último la llega a definir como "la España primitiva" (Ortega, 2016, p. 716). Una afirmación muy próxima a la que, en 1876, había plasmado Reclús refiriéndose a "Las Castillas, esta España por excelencian" (Ortega, 2016, p. 713). El mismo geógrafo anarquista francés había definido y detectado notables diferencias entre el centro y el litoral peninsular que marcaban una tendencia en la periferia a "vivir una vida independiente" (Ortega, 2016, p. 715) por lo que abogaba por el federalismo de la Primera República.

En el cambio de siglo la generación del 98 se suma al discurso reivindicativo de la Meseta y, por extensión, de Castilla con los conocidos trabajos de Unamuno, Maeztu y, algo más tarde, de Azorín (Casals, 2001). Todo ello mientras geólogos como Hernández-Pacheco y geógrafos como Dantín Cereceta popularizan la idea geológica y geográfica de la Meseta. Años más tarde esta reivindicación desembocará en planteamientos de todo signo, como la "España invertebrada" de Ortega o la degeneración franquista del tema. 
Esta primera tensión centro-periferia se intentó atajar, en el caso de Cataluña, con la constitución de la Mancomunitat de las cuatro diputaciones catalanas (1914) que la dictadura de Primo de Rivera primero intervino (1923) y posteriormente eliminó (1925). El segundo intento, anterior al levantamiento militar fascista, ya será el estatuto de autonomía republicano de 1932. Un primer estatuto de autonomía para Cataluña que fue suspendido por la CEDA en 1935, restablecido por el Frente Popular en 1936 y finalmente derogado por Franco en 1938.

a) ¿ Dos nacionalismos incompatibles?

Todos los procesos de legitimación nacional, ya sea el español, el catalán o cualquier otro, necesitan de algún tipo de energía ideológica que les alimente y justifique. Y este papel, en las sociedades modernas, lo han venido jugando los nacionalismos, la mayor fuerza centrípeta para la formación de los Estados modernos según Hartshorne (Taylor \& Flint, 2002, p. 167). Desde finales del siglo XIX, dos tipos de nacionalismos empezaron a rivalizar, el español y el catalán, pero dos nacionalismos que, con algunas excepciones, basan su legitimidad en argumentarios diferentes.

Los autores que han tratado esta cuestión coinciden en que el origen del nacionalismo, como fuerza ideológica esencial del estado moderno, es de origen postmedieval y no será hasta la Revolución Francesa (1789) cuando cristalizaron

los elementos de la idea nacionalista que habían ido germinando a lo largo de los dos siglos anteriores (Smith, 1979, p. 37).

Este primer tipo de nacionalismo de cuño inicialmente francés será teorizado por autores como Jean-Jacques Rousseau (1712-1778) y Giuseppe Mazzini (1805-1872). A este nacionalismo se debe la consolidación del llamado Estado científico/liberal que busca homogeneizar la población administrativa, lingüística y culturalmente en pro de la eficiencia (científica) fundamentada éticamente en el bienestar colectivo y el progreso. Aclarar a quién y hacia qué propósito se orienta este deseo de mayor eficiencia divide las opiniones en función de las distintas lecturas y enfoques políticos. Esta tipología de nacionalismo ha sido llamada territorial, estatista, liberal, funcional, voluntarista, policéntrical (Smith, 1976). Se trata de un proyecto que aspira a agrupar territorios policulturales y plurilingüísticos bajo un Estado que los unifique y homogenice.

Alternativamente a este nacionalismo funcional de cuño francés, el modelo de nacionalismo alemán de raíces románticas (Martínez, 1997) presenta planteamientos teóricos distintos a partir, especialmente, de las obras de Johann Gottfried von Herder (1744-1803) y Johann Gottlieb Fichte (1762-1814). Aquí el proceso se supone que tiene que formularse a partir territorios cultural y lingüísticamente homogéneos, de la nación como ente histórico, donde la lengua y las tradiciones 
populares -ambas de origen medieval- se opondrán al racionalismo más jacobino. En este caso la legitimidad del Estado deriva orgánicamente de la unidad cultural de los individuos y de su historia común y no del derecho divino como en el antiguo régimen o del objetivo de progreso como en la tradición posterior a la Revolución Francesa. El paisaje, la tradición, la lengua fueron las bases sobre las que se justificaron la nación legitimadora del Estado. Este segundo tipo de nacionalismo ha sido llamado romántico, orgánico, étnico, cultural, lingüísticol Si el nacionalismo de origen francés aspiró a la construcción de un Estado moderno a partir de diferentes naciones, el de origen germánico a lo que aspiraba era a que cada una de las naciones construyera su Estado moderno.

Mientras que las unificaciones alemana e italiana del siglo XIX se basaron en el modelo romántico y cultural, Estados como Francia, Gran Bretaña y España se asentaron sobre la base del nacionalismo funcional. Con ello occitanos, bretones, galeses, escoceses, vascos y catalanes, serán unificados bajo el común denominador de franceses, británicos o españoles ${ }^{13}$. En ambos enfoques la historia oficial jugó un papel determinante ya que, como se ha dicho, sin historia no puede haber nación (Taylor \& Fint, 2002, p. 251).

En el caso español y en los otros ejemplos citados, la decantación por uno u otro modelo de construcción nacional, más allá de los argumentarios de las historias oficiales, puede explicarse a partir de razonamientos de tipo socioeconómico, es decir, en función de los intereses defendidos por las diferentes élites en el momento de la construcción de los estados modernos:

Las áreas nucleares principales de España, Portugal, Francia e Inglaterra tenían una organización peculiar que equilibraba los intereses urbanos comerciales y los de los terratenientes, en tanto que en el resto de Europa predominaban unos intereses o los otros. En las antedichas cinco áreas nucleares principales, sin embargo, la autoridad central del Estado podía explotar la división de intereses existentes. Es la misma base de poder del Estado territorial a la que alude D. Smith. La consecuencia fue la creación de Estados intermedios en Europa Occidental que contrastaba con las ciudades-Estado dominadas por los intereses mercantiles en Europa Central y por los imperios dominados por los intereses de los terratenientes en Europa Oriental (Taylor \& Flint, 2002, p.165-166).

13 La evolución posterior de estos tres estados ha sido dispar, mientras que Francia se ha mantenido fiel al modelo original, Gran Bretaña ha retocado el modelo evolucionando hacia la autonomía asimétrica de Escocia, Gales e Irlanda del Norte. Por su parte España, a partir de la Constitución de 1978, ha sido donde más se ha transformado el modelo con la consolidación del Estado de las Autonomías. 
La construcción de los Estados modernos, basados en uno u otro modelo nacional y con fechas que podían variar notablemente, fue en paralelo a la fijación de las modernas fronteras interestatales y sus indispensables atributos simbólicos

(...) la fijación de las fronteras modernas comporta (...) importantes consecuencias en otros muchos planos, como el económico o el simbólico, siendo, en este último sentido, un mecanismo fundamental para la construcción de las identidades nacionales y, por ende, de los Estados-nación (García, 2019, p. 244-245).

Efectivamente, con el Estado moderno aparecen las fronteras modernas y

Si nos preguntamos por los límites externos de nuestro Estado-nación, debemos olvidarnos de mitos fundacionales como la importancia del Tratado de Alcañices o la tantas veces repetida noción intencionada de unidad nacional con los Reyes Católicos (Lois, 2019, p. 211)

En el caso español, sigue también este razonamiento Álvarez Junco, al señalar que la unificación política de principios del XVIII generó relativamente pocos problemas con las élites catalanas hasta 1898. Pero a partir de entonces, en la línea apuntada por Pierre Vilar y ya citada, estas detectan ineficiencias en el Estado español y, más allá del regionalismo, empiezan a crecer las voces reivindicativas de una nación catalana no coincidente con la española. Esta reivindicación catalana se basó evidentemente en el modelo romántico alemán y no en el funcional francés en que se fundamentaba (y se fundamenta) el Estado-nación español. Es entonces, a principios del siglo XX, cuando la romántica reivindicación lingüística emerge con fuerza y es en este contexto que debe situarse la sentencia de Joan Maragall la nació és la llengua (1907). ${ }^{14}$ Pero la lógica del nacionalismo romántico de vincular lengua y nación comportaba un problema no menor, el dominio lingüístico del catalán no coincidía, ni coincide, con Cataluña.

\section{b) El mapa lingüístico y el mapa político}

Si la lengua tenía que ser el eje central de la nación catalana (el metafórico pal de paller) se imponía, como tarea imprescindible, su inventario, catalogación y especialmente su cartografiado, ya que el mapa tiene también la función de prefigurar la realidad (Nel.lo, 2013, p. 49-50). Es precisamente a principios del siglo XX cuando se inician los grandes proyectos lingüísticos de

14 Carta de Joan Maragall a Pere Corominas (fragmento). 12 de julio de 1907. Disponible en línea en http://provisionals.blogspot.com.es/2010/10/llengua-nacio-individu.html. La frase es paralela a la de Fernando Pesoa Minha pátria é a língua portuguesa (1914). Disponible en línea en http://multipessoa.net/typographia/labirinto/multipessoa-bernardo-soares-19.pdf 
recopilación, valorización y reivindicación del catalán. Al respeto destacan dos iniciativas de inventariado y valorización de la lengua catalana, e indirectamente de la nación catalana, que se impulsaron desde el catalanismo. En ambas iniciativas tiene un papel fundamental el mallorquín Antoni Maria Alcover ${ }^{15}$ (1862-1932) vicario general y canónigo de la catedral de Mallorca. Personaje de gran iniciativa, rústico, carlista, agresivo, germanófilo, duro e intransigente polemista, fundador de la dialectología catalana, insigne romanista reconocido internacionalmente, políticamente muy conservador y seguidor de personajes tan controvertidos como Torras i Bages y Fèlix Sardà i Salvany.

La primera de estas incitativas fue la publicación, en 1901, de la llamada Lletra de convit (carta de invitación), dirigida a los estudiosos y amantes de la lengua catalana con el objetivo de recopilar y fijar el léxico del catalán cuando todavía no se disponía de una gramática unificada. El resultado recopilatorio vería la luz muchos años más tarde con la publicación del monumental Diccionari català-valencià-balear (Alvover-Moll, 1930-1962). El primer volumen vio la luz en 1930 y el último de los diez que componen la obra en 1962, ya en pleno franquismo. ${ }^{16}$

La segunda iniciativa a destacar fue la organización, en 1906, del Primer Congrés Internacional de la Llengua Catalana presidido por mismo Alcover. Al mismo asistieron 3000 congresistas

15 Para conocer al personaje y su obra pueden consultarse la biografía de su principal discípulo Francesc de Borja Moll (1962), así como la información contenida en https://alcover.iec.cat/, http://www.institucioalcover.org/index.php/ca/antoni-m-alcover-22941

y hitps://www.escriptors.cat/autors/alcoveram/vincles.php. Entre su multitud de trabajos cabe destacar la recopilación y literaturización de las Rondalles mallorquines, aparecen de forma escrita a partir de recopilaciones de la tradición oral publicadas en 24 volúmenes por Alcover bajo el seudónimo de Jordi des Recó a partir de 1880. La obra enlaza también con la tradición romántica de recopilación y estudio del folclore como forma de identificar y ensalzar la nación, en este caso una parte de la nación cultural, Mallorca.

16 El diccionario, popularmente conocido por sus siglas DCVB o Alcover-Moll, contó con más de 1600 colaboradores entre los que destacan el menorquín Francesc de Borja Moll -que de hecho dirigió directamente la obra desde la muerte de Alcover (1932) hasta la publicación del último tomo (1962) - el valenciano Manuel Sanchís Guarner y la hija de Francesc de Borja Moll, Aina Moll. Las desavenencias entre Alcover y Pompeu Fabra en relación a la codificación y estandarización de la lengua provocaron la ruptura (1918) del canónigo de Manacor con la sección filológica del Institut d’Estudis Catalans que el mismo presidía desde su fundación en 1911. En 1918 Alcover traslada el proyecto de diccionario a Mallorca, gestiona y consigue una ayuda de 25000 pesetas anuales entre 1920 y 1926 del gobierno central presidido primero por el también mallorquín Antonio Maura y, desde 1923, por el dictador Primo de Rivera. De esta fase data el cambio el nombre del diccionario del original Diccionari de la llengua catalana a Diccionari català-valencià-balear, un cambio reactivo frente al IEC que sería aprovechado por el gobierno central para favorecer un proyecto que, por ser de enfoque dialectológico y potencialmente segregacionista, se suponía que debilitaría la unidad y fortaleza de la lengua catalana. Los primeros volúmenes se publicaron en catalán no normalizado por el IEC pero posteriormente Francesc de Borja Moll sacó las ediciones en versión normativa de la ortografía de 1913 y la gramática de 1918 que Alcover inicialmente no aceptaba. Varios mecenas hicieron posible la publicación del monumental y costoso diccionario desde la postguerra hasta 1962, entre ellos hay que resaltar al ayuntamiento de Barcelona y, especialmente, a la Fundación Juan March. Hoy el Alcover-Moll puede consultarse en línea https://dcrb.iec.cat/ 
dedicados a la romanística y supuso la puesta de largo de la lengua catalana a escala internacional. Es precisamente en este congreso donde otro mallorquín, Joan Aguiló, presenta una comunicación que incluye el primer mapa del dominio lingüístico del catalán (Aguiló, 1908, entre las pp. 640 y 641) al que seguiría un segundo, que data de 1921, publicado con el primer volumen del ya mencionado Diccionari català-valencià-balear (Figura 1).

Figura 1. Los primeros mapas de la lengua catalana (1906 y 1921)

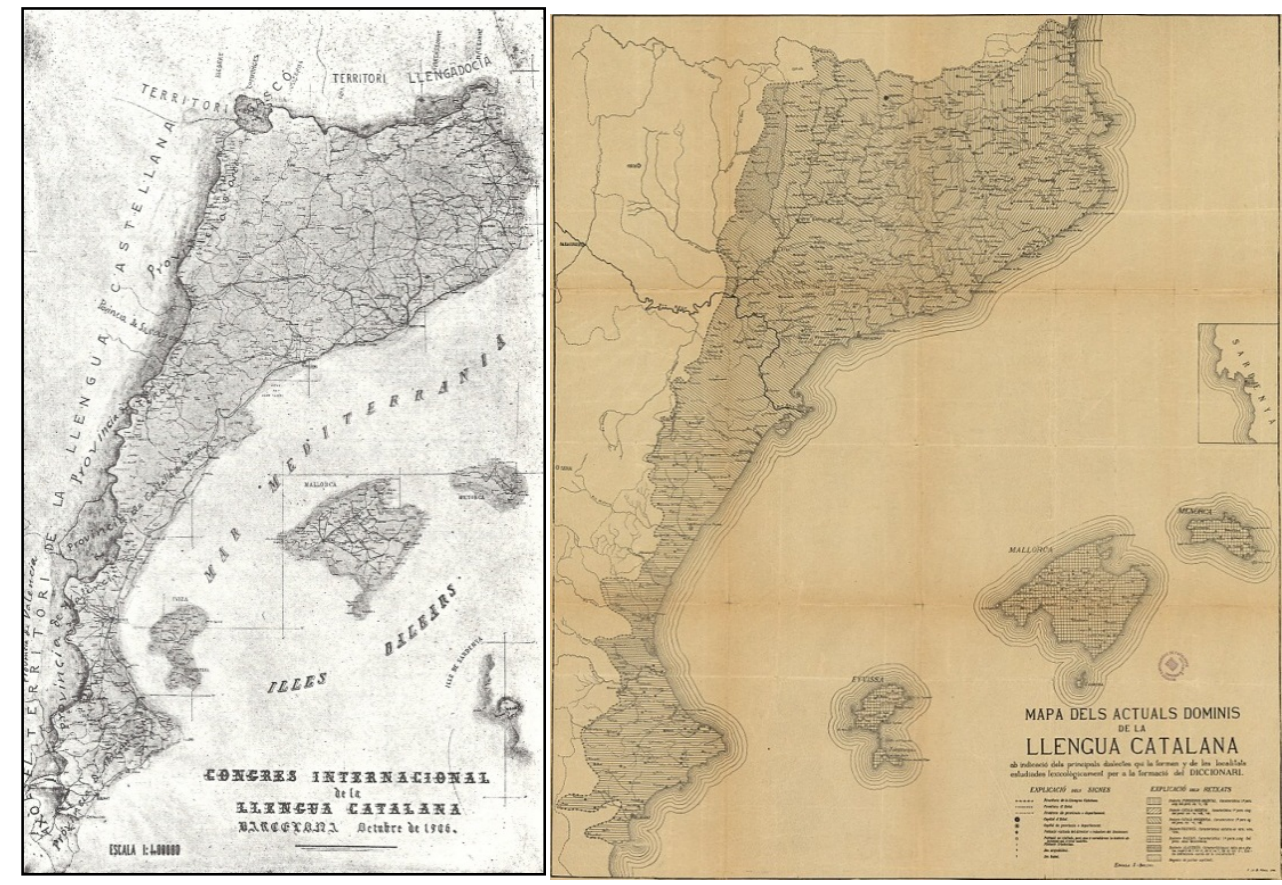

Fuente: Aguiló (1908 [1906], pp. 640 y 641) en Company (2013, April 19); Moll \& Alcover (1930 [1921], p. 62)

Pero estos primeros escarceos sobre el dominio lingüístico catalán son todavía claramente de enfoque regionalista, véanse al respeto lo que apunta Aguiló en la comunicación en la que se incluye el mencionado primer mapa del dominio lingüístico catalán:

Sin estas regiones [las de habla catalana] nuestra Nación [España] parece un cadáver (Aguiló, 1908, p. 638, traducción propia).

Regiones, por tanto, de la Nación española, del Estado-nación español, regiones explícitamente llamadas levantinas entre las que se incluye la tierras del llevant d'Aragó (la franja de Ponent en 
terminología catalana), lo que no deja de ser paradójico proviniendo de la pluma de un mallorquín centrado en la cartografía de la lengua catalana. ${ }^{17}$

El nacionalismo de raíz romántico-lingüística necesitaba un ámbito geográfico al que referenciar la nación si esta, como pregonaban los románticos, tenía que vincularse especialmente con la lengua. Este ámbito geográfico requería de un nombre que no podía ser Cataluña, de ahí que se propusiera Países Catalanes (Països Catalans) una denominación documentada por primera vez en 1876 pero que no se popularizará, como veremos, hasta un siglo más tarde. ${ }^{18}$

c) Proteccionismo, déficit fiscal y nuevas dinámicas político-económicas

Mientras la reivindicación lingüística iba madurando, el empresariado industrial catalán más influyente se protegía arancelariamente al tiempo que contribuía al sostenimiento económico del Estado soportando un calculado déficit fiscal. La política arancelaria que inicia Figuerola en 1869, tendrá continuidad con otras disposiciones del mismo signo, especialmente las del ministro Cambó (1922), que se prolongaron en sus principales líneas directivas prácticamente hasta la década de 1960, cuando la dictadura fascista ${ }^{19}$ superó una primera etapa autárquica para abrir sus mercados y ser reconocido internacionalmente al alinearse con el bloque capitalista occidental. Entre los muchos y variados efectos sobre la sociedad catalana de esta segunda etapa nos interesa aquí

17 Un geógrafo también mallorquín, Rafael Ballester y Castell (Colom, 1980), fue quien en 1916 planteó, en su Geografía de España, la denominación de levantina aplicada a la región valenciana. Sin embargo la denominación de Levante se consagra en la década de 1920 a partir especialmente de la obra de Juan Dantín Cereceta Ensayo acerca de las regiones naturales de España publicada en 1922 y la de Eduardo Martín Echevarría Geografía de España de 1928 (Casals, 2001; García, 2002, p. 332). En cualquier caso Levante es un término que Azorín ya venía utilizando, como mínimo desde 1910, en un artículo con este nombre aparecido en Diario de Barcelona (16/05/1910).

18 El topónimo es equivalente al de Euskal Herria aunque la toponimia nacional vasca y catalana difieren en cuanto a las tradiciones de los respetivos vocablos. Mientras el ámbito lingüístico del vasco, Euskal Herria, es una denominación tradicional, Euskadi, referido a las tres provincias de la actual comunidad Autónoma, es un neologismo propuesto por Sabino Arana en 1896 (Ruíz, 1991, p. 6; García, 2002, p. 662). La situación contraria se da en el caso catalán donde Cataluña es la denominación tradicional y para referirse al ámbito lingüístico común se propondrá Países Catalanes, Països Catalans. La denominación data de un tratado de historia del derecho foral del valenciano Bienvenido Oliver y Esteller de 1876 pero la popularización del topónimo, para defenderlo o para atacarlo, hay que atribuirlo a la propuesta de otro valenciano, Joan Fuster que, en 1962, publica el opúsculo Qüestio de noms y, sobre todo, Nosaltres el valencians (Fuster, 1962), un libro que inicialmente debía titularse Nosaltres els catalans. El término se imponía así a otras propuestas más complicadas desde fuera de Cataluña como Gran Catalunya o Catalunya Gran y a otras más complejas y exclusivamente lingüísticas como Països de Llengua Catalana. No han faltado las propuestas de llamar sencillamente Catalunya a todo el ámbito de los Países Catalanes, una propuesta de nuevo de origen valenciano (Guia, 1986).

19 El régimen franquista, después del golpe contra la República democrática, hizo un gran salto hacia atrás reivindicando el nacionalcatolicismo. Una reivindicación que aunó, bajo un único vocablo, la tradición unificadora religiosa anterior al estado moderno con la moderna tradición unificadora del Estado-nación territorial. Con su "Por Dios y por España" apeló contradictoriamente a una unidad basada en la religión premoderna (Dios) y, a la vez, en el Estado-nacional de la modernidad (España). 
destacar tres: los efectos lingüísticos y culturales de las migraciones internas españolas, la irrupción de los medios de comunicación de masas y la reacción cultural y editorial catalana.

La primera apertura de las fronteras económicas de las décadas de 1950 y 1960 supuso, entre otros aspectos geográficamente relevantes, un giro demográfico muy importante vinculado a las migraciones interiores. Como se ha apuntado

En la década de los 50, la provincia de Barcelona absorbió 241.906 inmigrantes del total de 258.717 del conjunto catalán (Burbano, 2012, p. 57).

y

Para el conjunto de la provincia de Barcelona, en el periodo de 1961 a 1970, se pasó de 2877966 a 3.929194 habitantes, lo que supone un aumento de 1051228 , de los que el crecimiento vegetativo es responsable de 401 631, y la inmigración de 649597 (Burbano, 2012, p. 61).

El impacto lingüístico y cultural derivado de esta llamada segunda oleada migratoria (Figura 2) erosionó duramente la vinculación romántica entre lengua y nación catalana. ${ }^{20}$

Figura 2. Migración y crecimiento demográfico en Cataluña (1903-2013)

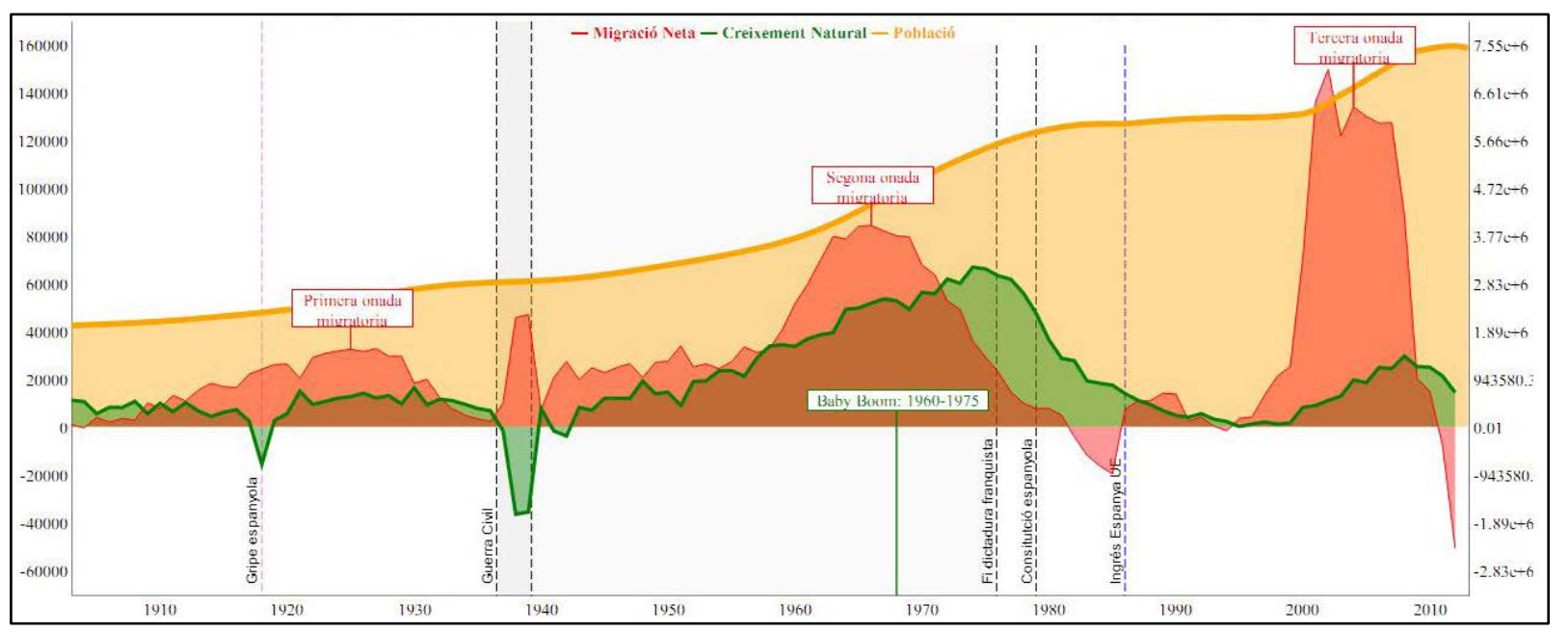

Fuente: Domingo (2014) en Barnosell (2015, January 1)

20 La población catalana ya había ganado más de 500000 habitantes como consecuencia de la inmigración entre las décadas de 1910 y 1930 (primera oleada migratoria, figura 2) lo que provocó, entre otros, la aparición de los primeros planteamientos racistas y xenófobos (Simon, 1997). Por su parte, el nacionalismo de izquierdas de la década de 1960 combatió estos planteamientos hasta el punto incluso de proponer la estelada vermella de claro posicionamiento izquierdista, frente a la tradicional de fondo azul. 
En paralelo a los datos demográficos cabe destacar también la irrupción de los medios de comunicación de masas. Mientras que tanto en 1968 como en 1975 el 76 \% de los hogares españoles disponían de radio, la televisión era presente sólo en el 38 \% de los hogares en 1968, un porcentaje que había ascendido al 79\% en 1975 superando a la radio (Ariño, 2017, p. 262). Una radio y una televisión en castellano que multiplicaron su alcance e influencia lingüística sobre toda la población.

Estos dos factores, combinados, ponían en crisis el modelo de nación catalana romántica, monocultural y catalanoparlante y, en la década de 1950, en plena dictadura franquista, hicieron surgir lecturas de la historia de Cataluña como la de Vicens Vives (1954) que acudieron al mestizaje para explicar la catalanidad, o las reflejadas en libros de éxito como Els altres catalans (Candel, 1964) $^{21}$ que reivindicaron explícitamente la catalanidad, también, de la población inmigrada. Planteamientos relativamente nuevos como los de Vicens o de Candel favorecerían, en Catalunya, el surgimiento de enfoques nacionalistas no exclusivamente románticos.

Pero en la década de 1960, políticamente dictatorial pero con nuevos aires económicos liberalizadores, vieron la luz varias iniciativas que recobraron e impulsaron la reivindicación lingüística y nacional en un momento en que la segunda oleada migratoria (figura 2) de castellanoparlantes y los medios de comunicación reformulaban el contexto sociolingüístico. Era la reacción catalana en el contexto de crecimiento económico de los años sesenta. Y así -a caballo entre el franquismo y la democracia- cabe destacar la publicación, entre 1969 y 1983, de la Gran Enciclopèdia Catalana, la GEC 22 . La GEC en su papel de gran enciclopedia nacional, fue quien codificó el mapa "oficial" de los Países Catalanes. Dicho mapa plantea una demarcación nacional con varias incoherencias (Figura 3) al agrupar entidades administrativas diversas (departamentos franceses, provincias españolas, comarcas, municipios, ciudades, estados】) con el único denominador común de la presencia en todo o parte del territorio de la lengua catalana ${ }^{23}$.

21 El libro, de gran éxito, se elaboró a partir de un artículo periodístico escrito en castellano, Los otros catalanes, publicado originalmente en 1958.

22 La iniciativa data de 1965 y fue impulsada inicialmente por Max Cahner (historiador de la lengua), Jordi Carbonell (filólogo), Enric Lluch (geógrafo) y Ramon Folch (biólogo). La primera edición se cierra, ya en período democrático, en 1983 con el volumen 16 si bien se publicaran sucesivos suplementos hasta 2009. A partir de 1998 la obra se traslada progresivamente a la versión on line http://www.enciclopedia.cat/

23 El ámbito (Figura 3) incluye completamente el departamento francés de los Pirineos Orientales (Catalunya Nord), lo que supone incorporar la occitana Fenolleda; toda la provincia de Lérida, con el también occitano Val d'Aran; la llamada, desde Cataluña, Franja de Ponent y, desde Aragón, Franja Oriental, son las comarcas aragonesas catalanoparlantes de las provincias de Huesca, (la Ribagorça y la Llitera), Zaragona (el Baix Cinga) y Teruel (el Matarranya); en el caso del País Valenciano se incluyen enteras las tres provincias, lo que supone la inclusión de las zonas castellanoparlantes de Castellón (Olocau del Rey, Alto Mijares y Alto Palancia), Valencia (los Serranos, 
Figura 3. Los Países Catalanes según la Gran Enciclopedia Catalana (1969) y los desajustes entre las fronteras lingüísticas y administrativas

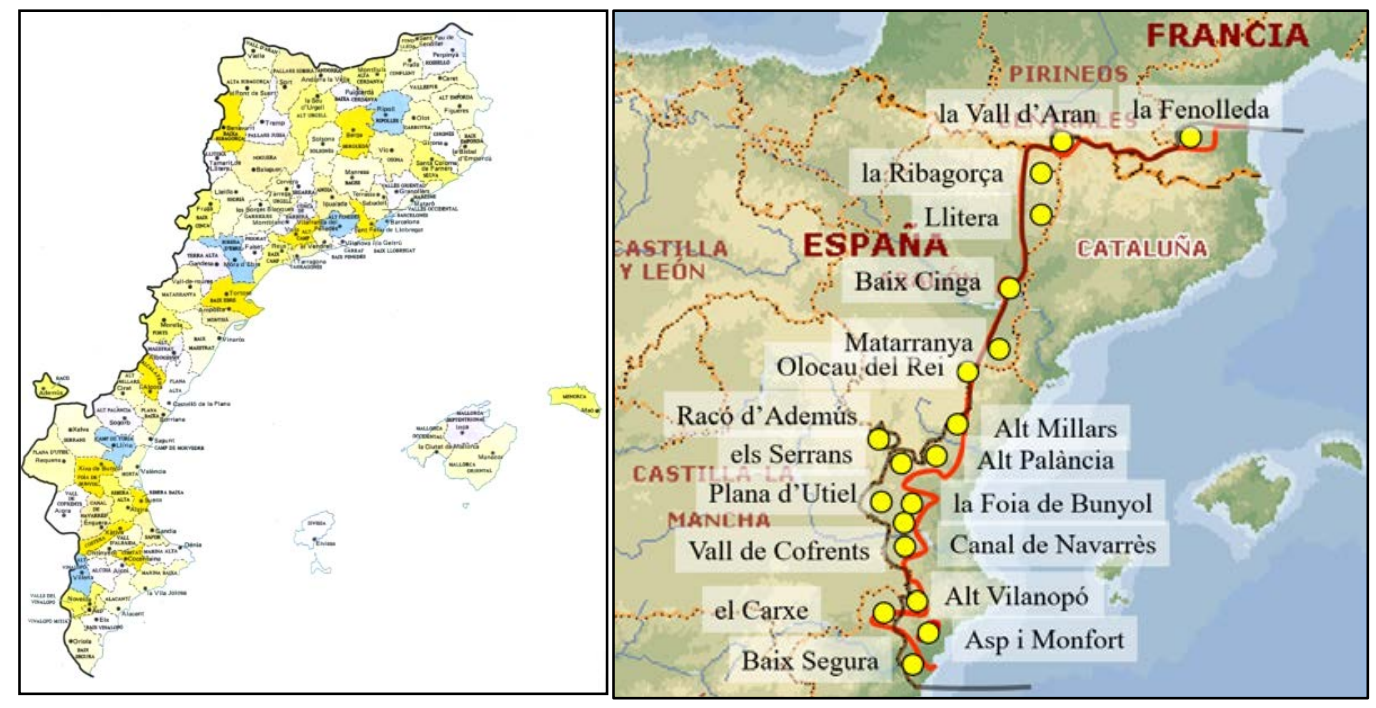

Fuente: elaboración propia a partir de Gran Enciclopèdia Catalana (1969)

\subsection{Diversidad entre 1979 y 2017}

La GEC, editada a caballo entre la dictadura y la democracia, ha sido calificada por Ramon Folch, uno de sus impulsores, como la primera "estructura de estado". ${ }^{24}$ Pero la GEC, propiedad del grupo y fundación Enciclopèdia Catalana desde 1980, ha formado parte de un proyecto más amplio. En efecto, desde Encilopèdia Catalana, además de la GEC, se han impulsado otros importantes proyectos editoriales todos ellos en clave nacional de los Países Catalanes. Destaquemos aquí las grandes obras enciclopédicas Història Natural del Països Catalans (19841992) dirigida por Ramon Folch en 16 volúmenes, los 13 volúmenes de la Història. Polífica, Societat i Cultura dels Països Catalans (1996-2008) dirigida por Borja de Riquer o los 7 volúmenes de la Geografia General dels Països Catalans (1992-1996) y el Atles Universal Català (1984, renovado en 1992) que dirigió Carles Carreras. Historia natural, geografía, historial nacionalismo romántico de fondo pero con una demarcación no estrictamente lingüística que quiere prefigurar un Estado-nación funcional no coincidente con los límites de la lengua catalana.

Rincón de Ademuz, Requena-Utiel, Hoya de Buñol, Canal de Navarrés y Valle de Cofrentes) y Alicante (varios municipios del Alto Vinalopó, municipios de Aspe y Monforte y comarca del Bajo Segura). Por el contrario dos enclaves con presencia del catalán no son incluidos en los mapas de la GEC, el Carche (el Carxe) y Alguer (l'Alguer). La repoblación valenciana, posterior a la expulsión de los moriscos, de la comarca murciana del Carche (siglo XVII) aportó a la comarca el catalán de los valles del Vinalopó. Por su parte el Alguer fue repoblado por colonos catalanes en el siglo XIV en el contexto del dominio y colonización medieval catalanoaragonesa de Cerdeña.

24 Ver http://rumiar-hi.blogspot.com.es/2015/12/potser-la-primera-estructura-destat.html?m=1 
El proyecto político de los Países Catalanes no ha ido más allá de algunos acuerdos vinculados a la promoción de la cultura catalana a los que se han ido sumando o desligándose la Comunidad Valenciana y las Islas Baleares en función de los vaivenes de los partidos políticos de cada legislatura. Los partidos de derechas, especialmente los valencianos, se han mostrado muy beligerantes y centrados en esta cuestión hasta el punto de provocar la llamada "batalla de Valencia" y conseguir que la Constitución del 78 prohibiera expresamente la federación de las comunidades autónomas (artículo 145.3) en un claro y reconocido interés por impedir la federación entre Cataluña, Comunidad Valenciana y las Islas Baleares (García, 2002, pp. 495499).

En cualquier caso será la recuperación de la autonomía con la aprobación del estatuto de 1979 lo que permitió avanzar en políticas que aspiraron a construir contextos favorables a la lengua y cultura catalana. Efectivamente, el estatuto de 1979 además de materias relacionadas con el estado del bienestar, hizo posible administrar competencias que podían forjar la nación romántica y cultural, no el Estado-nación funcional al no otorgar competencias de defensa, fiscales, económicas, judiciales $\square$ El monopolio de la fuerza (ejército, policíal) y de la extracción de renta (Hacienda) se quedaban en manos del Estado. Todo ello cuando, a partir de la década de 1980, la realidad sociológica catalana poco tenía que ver con la de principios del siglo XX (Domingo, 2014) en el que lo lingüístico era la punta de lanza del movimiento nacionalista burgués catalán.

En consecuencia las políticas desarrolladas a partir de 1979 no podían ir mucho más allá de las que giraban en torno al eje central o pal de paller de la lengua. Así lo demuestra que dos de los temas que más salen a la palestra a raíz del conflicto institucional generado en la legislatura catalana 2016-2017 sean, por un lado, la escuela catalana y su política de inmersión lingüística ${ }^{25}$ y, por otro, la política de medios de comunicación públicos y en catalán desarrollada a partir de la Corporació Catalana de Mitjans de Audiovisuals (CCMA), ${ }^{26}$ seguramente los dos aspectos más exitosos de la administración autonómica en el intento de vertebrar la nación en torno a la lengua

25 El catalán pasó a ser asignatura obligatoria en Cataluña a partir de 1978, la aprobación de la ley de normalización lingüística (1983) posibilitó que, a partir del curso 1983-1984 se implantara la inmersión lingüística inspirada en la del Quebec que data de 1965. La inmersión lingüística catalana se ha definido como total, primeriza (se implanta desde el inicio de la escolarización) y no segregadora (no separa los alumnos por lenguas). Ha sido reconocido internacionalmente como modelo de éxito. Para ver la situación real y oficial del catalán y otras lenguas españolas pueden consultarse los trabajos de Jesús Burgueño (1997 y 2002).

26 Aunque las emisiones en catalán de radio y televisión son anteriores, no será hasta 1983 con la constitución de la Corporació Catalana de Mitjans Audiovisuals (CCMA), que salgan a antena TV3 y Catalunya Ràdio. Aunque el mapa audiovisual se ha expandido enormemente desde la liberalización del sector en 1988 -seis años después de la CCMA- TV3 conserva unos importantes niveles de audiencia, especialmente reconocidos por lo que se refiere a los informativos. 
catalana. A la escuela catalana y a TV3, una parte de la clase política española, se les hace responsable de la desafección a España de una parte de la población catalana. Una desafección que se supone sobrevenida como consecuencia de las políticas impulsadas por la Generalitat desde 1979, especialmente por lo que hace referencia a los dos campos mencionados. No obstante tanto la escuela catalana como los medios de comunicación públicos alcanzan, en Cataluña, un nivel de consenso político que va más allá del independentismo y del que sólo se excluyen PP, Cs y Vox. ${ }^{27}$

Por lo que hace referencia a los medios de comunicación parece evidente que el discurso mayoritario fuera de Cataluña que asegura que los medios independentistas, con TV3 a la cabeza, manipulan la opinión pública, es más que matizable y se basa en suposiciones no contrastadas con datos. Las audiencias de los canales de la CCMA no alcanzan el 18\%, frente al 9,2 de TVE y el $61,5 \%$ de las televisiones privadas. En cuanto a los periódicos los que pueden considerarse favorables a la independencia cuentan con 577000 lectores y los contrarios 1696000 . Esto significa que

la población de Cataluña ve cuatro veces más canales de televisión españoles que catalanes y que lee tres veces más diarios contrarios a la independencia que los que son, teóricamente, favorables. (Sampol, 218, p. 23, traducción propia)

Este y otros datos cuestionan el supuesto "éxito" de las políticas a favor del catalán en Cataluña. Por una parte la irrupción de las televisiones privadas a partir de su primera regulación/liberalización (1988) ha incrementado mucho más la oferta en castellano que lo que lo ha hecho TV3 en catalán. Por otra parte suele olvidarse que por lo que respeta al uso habitual de las lenguas en Cataluña el castellano avanza sobre el catalán. Así lo demuestra el dato que refleja que, entre 2003 y 2018, los que manifiestan tener el catalán como lengua habitual se sitúa en la banda del 35-36 \% de la población mientras que los que su lengua habitual es el castellano oscilan entre el $45-50 \%^{28}$ en el contexto de la llamada tercera oleada migratoria (Figura 2) y dependiendo de los flujos y reflujos de la misma.

En los últimos decenios del siglo XX el modelo de nación romántica, basada en la lengua como eje fundamental, dio paso lentamente a modelos que aspiraban a constituir un Estado-nación internamente diverso. Es cuando se empieza a repetir el mantra de Jordi Pujol, de que son

27 Según fuentes periodísticas parece ser que fue el PSC quien situó la línea roja de aplicación del 155 en la escuela catalana y la CCMA.

28 Ver https: //www.idescat.cat/pub/?id=eulp\&n=3202\#Plegable=geo 
catalanes todos los que viven y trabajan en Cataluña y quieren serlo. ${ }^{29}$ En esta frase ha desaparecido la alusión a la lengua catalana, el pal de paller del catalanismo desde sus orígenes, las aspiraciones nacionales más ambiciosas no podían basarse en la nación lingüística, debían hacerlo en la nación funcional, policéntrica y voluntarista que habían seguido las experiencias francesas, británicas o españolas máxime cuando la inmigración no catalanoparlante seguía sumando. ${ }^{30}$ Había trascurrido más de un siglo desde la sentencia la Nació és la llengua de Joan Maragall. El choque de trenes, tarde o temprano, estaba anunciado.

Este lento cambio de rumbo, que conduce a posiciones enfrentadas entre catalanismo y españolismo, se va activando a partir del despliegue del estatuto de 1979 que coincide con la incorporación plena del Estado español a las estructuras políticas europeas (1986) y la formación de las grandes élites empresariales (españolas y catalanas) que empezaron a competir en un mundo cada vez más globalizado. Por lo que afecta al caso catalán el contexto institucional generará una situación nueva que, sumada a la política "radial" de las inversiones del Estado (Bel, 2010, pp. 163-236), provocará sonoras desavenencias entre Cataluña y el Estado español.

Un parte mayoritaria del gran empresariado y grandes corporaciones catalanas apuestan claramente por seguir vinculadas al Estado y beneficiarse de él en el contexto global con una única enmienda: complementar la radialidad de las infraestructuras con más transversalidad y con el corredor mediterráneo como reivindicación más emblemática. Una reivindicación que, con importantes matices, une la derecha unionista valenciana con la izquierda independentista catalana. La razón parece clara, no puede desaprovecharse una situación en la que el Estado español ha pasado a ser uno de los que pueden influir y decidir en política económica europea.

Por su parte el pequeño y mediano empresariado entiende que la desaparición de la protección arancelaria ya no justifica la transferencia de recursos que, vía déficit fiscal, salen y no regresan a Catalunya. Ante este nuevo escenario el independentismo tenía mucho terreno por recorrer.

Desde el punto de vista territorial hay que destacar un dato, el independentismo tradicional, de raigambre romántica y cultural, ha contado con sus mejores foros en comarcas y en los municipios

29 La frase aparece en La immigració, problema i esperança de Catalunya (1976) que recoge otros textos, entre ellos el "Comentari a Els altres catalans" de Candel, que había salido en Serra d'Or (junio de 1964), y que ya había anticipado en otro texto divulgado en ciclostil del 1958: "per català entenc tot home que viu i treballa a Catalunya, i que, de Catalunya, en fa casa seva, el seu país, al qual s'incorpora i és reconeix". Posteriormente, con alguna, variante aparecerá en otros discursos y escritos suyos. Debemos esta detallada información a Josep Oliveras quien muy amablemente nos la ha proporcionado.

30 Entre el año 2000 y 2010 la población catalana se incrementó en 1,2 millones de habitantes de procedencia extracomunitaria (Font, 2013, p. 38). 
más rurales. Por su parte el unionismo dónde más ha cuajado ha sido en los ámbitos costeroturísticos y metropolitanos, allí donde las nuevas actividades económicas reemplazaron a las tradicionales sobre las que se apoyaba gran parte de la nación romántica y donde mayoritariamente se asentaba la nueva población inmigrada (figura 2). Esta situación en parte parece ser que podría estar cambiando al virar una parte de las clases subalternas hacia planteamientos rupturistas con el Estado como forma, indirecta, de ruptura con el sistema y el régimen del 78 (Sánchez \& Puente, 2017, December 28). De cualquier forma, en el caso concreto de Barcelona, sigue observándose la pauta ya comentada de un mayor calado de las opciones independentistas en barrios sin segregación extrema y las unionistas en los vulnerados y acomodados (Nel.lo \& Gomà, 2018, p. 12). Un fenómeno paralelo al que se observa con otros fenómenos políticos a escala europea.

De todas maneras la nueva arquitectura político-administrativa que se construye a partir de la década de 1980 ha cambiado las relaciones de poder territorial y ha abierto nuevos escenarios de potencial conflicto no sólo en el ámbito lingüístico y cultural. Mientras el Estado delega en las comunidades autónomas un número importante de competencias domésticas relacionadas con la cultura y el estado del bienestar como sanidad y educación (Lois, 2013, p. 70), este mismo Estado cede competencias tan propias del Estado-nación como la defensa - con la entrada en la OTAN en el mismo 1986- y la política monetaria que se consumará con la sustitución de la peseta por el euro (2000). En el primer caso se trata de una delegación que, con la aplicación del artículo 155 de la Constitución, se ha podido comprobar que no es irreversible y en el segundo de lo que se trata es de una gestión confederal ya que la Unión Europea no va mucho más allá de una libre asociación entre estados a la que se pertenece de forma voluntaria y de la que se puede salir unilateralmente como se ha constatado con el Brexit.

Todos estos cambios institucionales vinculados, por una parte, a la incorporación al proyecto europeo y, por otra, a las políticas internas (infraestructuras, déficit fiscall) han enrarecido las relaciones Cataluña-España. El intento de articular un nuevo modelo de relaciones, a la luz de los cambios comentados, era el estatuto de 2006 que, entre otros aspectos, pretendía blindar las cuestiones lingüísticas e identitarias así como asegurar que el déficit fiscal no superara determinados indicadores en línea con otros modelos europeos como el alemán. Pero la sentencia del Tribunal Constitucional de 2010 lo abortó activando los posicionamientos políticos más enfrentados, unos posicionamientos que se han demostrado rentables electoralmente, en Cataluña para los partidos independentistas y en España para los unionistas. 


\section{Conclusiones y perspectivas después de la aplicación del artículo 155 de la CE}

Tres conclusiones generales se desprenden de lo expuesto hasta aquí. La primera en relación al papel de geografía española en el debate sobre la organización territorial y geopolítica en referencia a la cuestión catalana, la segunda relativa específicamente al conflicto Cataluña-España y la tercera acerca del contexto económico global en el que se asienta el conflicto.

\subsection{La geografía española y la cuestión catalana}

En cuanto a la primera cuestión cabe destacar que les aportaciones al debate han sido poco importantes. Sí que ha habido aportaciones en cuanto a la organización interna del Estado pero estas llegaron tarde al debate, llegaron cuando estaba prácticamente decidido el mapa de Comunidades Autónomas fruto de la Constitución de 1978. Pero sobre la conveniencia o no de mantener las actuales fronteras exteriores del Estado, desde la geografía, apenas se localiza bibliografía. En los encuentros de Valladolid (1979), Gerona (1989), en el número 32 del BAGE (2001), Toledo (2013) o Concentaina (2018) abundan los análisis generalistas y mayoritariamente enfocados "hacia dentro" del Estado cuyas fronteras no se cuestionan. La explicación de tal hecho hay que buscarlas, en parte, en el relativamente poco desarrollo es España de la geografía histórica, cultural o política (ninguno de estos tres campos tienen grupo constituido en el seno de la $A G E)$ que serían los campos de los que se esperarían más respuestas y planteamientos a la luz del conflicto catalán. La geografía regional española no ha discutido ni cuestionado el Estado y sus fronteras, sólo su organización interna, y la geopolítica, que lo podría haber hecho, está prácticamente desaparecida. Una desaparición que ha sido general en casi todos los continentes después de la II Guerra Mundial (Taylor \& Flint, 2002, p. 53) y que, en España, sólo en los últimos años vuelve a asomar.

\subsection{Sobre escenarios políticos no reivindicados}

En cuanto a la segunda cuestión -el conflicto territorial en sí mismo-las conclusiones no pueden ser más que provisionales. Una provisionalidad que puede imputarse en gran medida a la primera conclusión que acabamos de exponer y de la que se derivan posicionamientos enfrentados sin exploración de alternativas.

Según Javier Pérez Royo, la intervención de la Generalitat en aplicación del artículo 155 de la Constitución de 1978 día el 27 de octubre de 2007, cierra la etapa del Estado de las Autonomías o, como mínimo, la cierra en los términos que la veníamos conociendo hasta ahora. Fracasados los 
intentos reformistas como el neoregeneracionismo impulsados desde Cataluña (Cambó, operación Rocal) o el intento de pacto fiscal de 2012 (Font, 2013, pp. 34-5) y fracasados también los planteamientos más radicales como la Declaración Unilateral de Independencia (DUI) de 2017, el actual arco político catalán presenta dos bloques claramente diferenciados, el autonomista/federal (PP, Cs y PSC) y el independentista (JPCAT, ERC y CUP) con algunos posicionamientos intermedios (Comuns). El primer bloque acusa al segundo de separatismo y el segundo al primero de despendentismo ${ }^{31}$.

Los matices en el interior del bloque federalista/autonomista apenas se perciben y no faltan los que asimilan Estado de la autonomías a Estado federal (Zoido, 2013, p. 142; Mała, 2013, pp. 150-162). De hecho la aplicación del 155 en gran parte ratifica esta tesis al ser este artículo, como recuerdan los constitucionalistas, una casi copia literal del artículo 37 de la Constitución alemana, una constitución inequívocamente federal.

El bloque independentista ofrece menos matices, a lo que aspira es a la formación de un Estadonación europeo nuevo demarcado por la actual comunidad autónoma y que prescinde del resto de nación romántica que representan los Países Catalanes, aunque los partidos de este bloque no renuncian a la vinculación y "colaboración" federal o confederal con el resto de comunidades catalanoparlantes.

Aparte de estas dos posiciones apenas se exploran y reivindican otras alternativas como, por ejemplo, el federalismo plurinacional (Gragnon, 2001; Máiz, 2006) o la confederación. Como se ha señalado (Taylor \& Flint, 2002, p. 184-5), entre el estado unitario y la separación, además del Estado federal, está la asociación confederal. Entendida esta como una libre asociación que, a diferencia de las federaciones, sus miembros conservan el derecho a abandonarla. De la confederación se puede salir libremente y entrar en ella a condición de la admisión por parte de los confederados. Se trata de un pacto no impuesto que ha sido defendido también desde posiciones federalistas (Nel.lo, 2013, p. 49; Mata, 2013, p. 154) con reconocimiento explícito incluso del derecho de secesión (Mata, 2013, p. 155). Se trata de un planteamiento político equivalente al vigente actualmente en la Unión Europea donde no hay posibilidad de intervención al estilo del artículo 155 y en el que los estados miembros pueden decidir libremente la salida de

31 En esta acusación mutua se hace necesario una aclaración terminológica. Lo contrario de la separación es la unión, que es un término comúnmente admitido como positivo; por su parte lo contrario de la independencia es la dependencia, un vocablo de connotaciones negativas. De ahí que independentismo y separatismo no sean vocablos intercambiables como habitualmente se pretende desde algunos sectores. Mientras es viable, o como mínimo planteable, una unión entre independientes no se puede plantear una separación entre dependientes. 
la Unión activando, unilateralmente, el artículo 50 del Tratado de la Unión como se ha visto en el caso del Reino Unido.

Sería un modelo asimétrico no generalizable a todas las comunidades autónomas y que, incluso, podría plantearse a escala ibérica. Se trataría de una especie de "ampliación de capital" justificable especialmente en términos de coordinación de políticas hidráulicas o de infraestructuras de trasporte. ${ }^{32}$

\subsection{El conflicto en contexto global}

Sea esta u otra la salida al conflicto Cataluña/España lo que no puede obviarse ni soslayarse es que en la posmodernidad las relaciones cotidianas ya no son de escala local como en las antiguas sociedades agrarias o regional como en las industriales. La sociedad actual funciona a partir de grupos etnolingüísticos geográficamente discontinuos al tiempo que es gobernada más por los mercados que por los gobiernos (Lois, 2013, p. 67) en un claro proceso de desnacionalización (Boira, 2013, p. 105). Se vive en redes y ya no tanto en lugares y, en consecuencia, la clásica acusación de ineficiencia al gobierno central por su ubicación desconectada de la periferia más productiva deja de tener sentido. De alguna manera puede concluirse que, en realidad, el conflicto de España con Cataluña lo es con el llamado deep state, y que el Estado-nación se está transformando en el contexto de la emergencia del Estado postmoderno, el Estado-red de Manuel Castells (1998, April 20). Si los Estados-nación se reescalaron en su momento por encima de las naciones, ahora el Estado-red lo está haciendo por encima de los Estados-nación.

Pero frente a quienes sostienen este enfoque existen otras visiones (Castells \& Himanen, 2002) que resaltan la gran paradoja: el retorno de las naciones y el resurgir de las identidades precisamente como respuesta a la globalización homogeneizadora. De hecho las señales de repliegue en forma de nacionalismo político y económico que emiten muchas sociedades como las occidentales apuntan en esta segunda dirección ya que la globalización también refuerza, reactivamente, los nacionalismos. Sin ir más lejos, el conflicto aquí analizado podría interpretarse también en términos de repliegue ante las fuerzas globalizadoras una vez debilitado el Estadonación surgido después de la II Guerra Mundial.

Este nuevo contexto global contrasta con la lectura geográfica más meseteña de la península Ibérica como una casi-isla de la que procede nuestra antigua tradición hoy ya superada (el castillo

32 Esta hipotética Confederación Ibérica, reivindicada desde antes de la Guerra Civil, tendría la ventaja y activo, para los catalanes, de un trato equivalente al de Portugal y, para los españoles, de la ampliación territorial. 
almenado popularizado por Ángel Cabo). Dicha tradición implica una visión no neutral de las relaciones que se han dado en la península. Las islas reúnen la doble condición de lugares de tránsito y a la vez de aislamiento y, en el caso de la península, al aislamiento meseteño se opondría al tránsito periférico. Es la península Ibérica la isla, no la Meseta.

Se ha argumentado (Molinas, 2012, March 4) que el funcionarial y aislado Madrid, sin puertos ni ríos navegables, en su momento habría resultado ineficiente a la expansión económica según la lectura periférica. Ciudades como Barcelona, Sevilla/Cádiz, Lisboa o Bilbao, totas ellas a extramuros del castillo almenado y acumulando la mayor parte del PIB, hubieran conjugado poder político y económico y, supuestamente, hubieran resultado más eficientes para los intereses de las élites. Pero hoy esta lectura ya ha perdido gran parte de su sentido, si son los mercados quienes gestionan la "riqueza de las naciones" y, entre ellos, los mercados financieros, ya no hace falta contar con puertos para el intercambio comercial, basta tener aeropuerto internacional, buenas telecomunicaciones y estar bien posicionado en la jerarquías globales. En este nuevo contexto geopolítico postmoderno recobran fuerza las palabras de 2001 de Pasqual Maragall: "Madrid se va" (Margall, 2001, February 27). Y es que en una hipotética confederación que estabilizara el conflicto aflorarían problemas de mayor calado si se intentaran alternativas verdaderamente soberanistas frente a las redes y mercados globales.

Agradecimientos: Este trabajo se presentó, en su primera versión, en el encuentro "De la radialidad a la red. Nuevas perspectivas para el análisis, el planeamiento y el gobierno del territorio ibérico", celebrado en la Universidad de Barcelona, los días 20-21 de abril de 2018. El trabajo ha sido posible, entre otros, gracias al proyecto El conflicto urbano en los espacios de reproduccion. La vivienda como escenario de conflictividad social. Financiado por el Ministerio de Ciencia, Innovación y Universidades. Agencia Estatal de Investigación (RTI2018-094142-B-C22).

Declaración responsable: Las/os autoras/es declaran que no existe ningún conflicto de interés con relación a la publicación de este artículo. Las tareas se han distribuido de la siguiente manera: el artículo ha sido coordinado por Onofre Rullan. Las/os dos autoras/es han participado en la revisión bibliográfica y la redacción del artículo. 


\section{Bibliografía}

AGE (1980). La región y la Geografía Española. Valladolid: Asociación de Geógrafos Españoles. Aguiló, J. (1908). Fronteres de la Llengua Catalana y Estadística dels que parlen en català, In Primer Congrés Internacional de la Llengua Catalana. Barcelona Octubre 1906. (pp. 638-643) Barcelona: Estampa d'En Joaquim Horta. Retrieved from https://archive.org/details/primercongrsin00conguoft

Alcover, A. Mª, \& Moll, F. de B. (1930-1960). Diccionari Català-Valencià-Balear. Palma: Editorial Moll. 10 volúmenes.

Álvarez, J. (2018). Verdades como puños sobre los orígenes del catalanismo. Revista de Libros, (marzo). Retrieved from https://www.revistadelibros.com/articulo_imprimible.php?art=5403\&t=articulos

Álvarez, J. (2001). Mater Dolorosa. La idea de España en el siglo XIX. Madrid: Taurus Ediciones. Ariño, A. (2017). Tendencias sociales y culturales. In Romero J. (coord.). Geografía Humana de España. Curso de introducción (pp. 216-289). Valencia: Tirant Humanidades.

Arrighi, G. (1999). El largo siglo XX. Dinero y poder en los orígenes de nuestra época. Madrid: Akal Ediciones.

Barnosell, G. (2015, January 1). Andreu Domingo: Immigració i identitat a Catalunya. In Història! Bloc de Genís Barnosell. Retrieved from https://genisbarnosell02.wordpress.com/2015/01/08/andreu-domingo-immigracio-iidentitat-a-catalunya/

Bel, G. (2010). España, capital París: Origen y apoteosis del Estado radial: del Madrid sede cortesana a la capital total. Barcelona: Imago Mundi.

Boira, J. V. (2013). Infraestructuras y financiación en España, hacia un nuevo paradigma. In J. Gómez, R. C. Lois \& O. Nel.lo (Eds.), Repensar el Estado. Crisis económica, conflictos territoriales e identidades políticas en España (pp. 101-113). Santiago de Compostela: Universidade de Santiago de Compostela.

Burgueño, J. (1996). Geografía política de la España constitucional. La división provincial. Madrid: Centro de Estudios Constitucionales. 
Burgueño, J. (1997). Geografia lingüística d'Espanya, Treballs de la Societat Catalana de Geografia 44 , $35-57$

Retrieved

from http://revistes.iec.cat/index.php/TSCG/article/view/37119/37102

Burgueño, J. (2002). El mapa escondido: las lenguas de España. Boletín de la Asociación de Geógrafos Españoles, 34 , $171-192$.

Retrieved from http://www.ub.edu/gehc/pdf/mapaEscondido.pdf

Burbano, J. A. (2012). Las migraciones internas durante el franquismo y sus efectos sociales: el caso de Barcelona. Madrid: Universidad Complutense de Madrid. Retrieved from http://eprints.ucm.es/26437/1/TAD_Migraciones\%20internas\%20franquismo_F\%C2\%BA \%20Andr\%C3\%A9s\%20Burbano.pdf

Candel, F. (1964). Els altres catalans. Barcelona: Edicions 62.

Canova, N., Claval, P., \& Lois, R. (2018). Epistemología comparativa de los enfoques culturales en las geografías francesa y española. Cuadernos Geográficos, 57(3), 15-35. Retrieved from http://revistaseug.ugr.es/index.php/cuadgeo/article/view/5843

Casals, V. (2001). Ciencia, política y territorio. La construcción del paradigma regional en la península ibérica. Scripta Nova. Revista Electrónica de Geografía y Ciencias Sociales, 79, Retrieved from http://www.ub.edu/geocrit/sn-79.htm

Casas, J. M. (1980). La regionalización geográfica de España. In AGE, La región y la Geografía Española (pp. 163-178). Valladolid: Asociación de Geógrafos Españoles.

Castells, M. (1998, April 20). El Estado red. El País. Retrieved from https://elpais.com/diario/1998/04/20/opinion/893023211_850215.html

Castells, M., \& Himanen, P. (2002). La sociedad de la información y el Estado del bienestar: el modelo finlandés. Madrid: Alianza.

Colom, A. (1980). Un regenacionista mallorquí: Rafel Ballester i l'ensenyament de la geografía. Trabajos de Geografía, 37, Retrieved from http://ibdigital.uib.es/greenstone/collect/treballsGeografia/index/assoc/Treballs/_de_G eog/rafia_19/80v37p06.dir/Treballs_de_Geografia_1980v37p063.pdf

Company, R. (2013, April 19). Un calaix de sastre. Un espai propi i, potser, compartit. I, últimament, ja no tan carregat de política. In Rafael Company, ciutadà. Retrieved from http://rafaelcompany.blogspot.com.es/2013/04/1906.html 
Contreras, G. A. (2013). Informe del Grupo de Trabajo de Estudios Regionales. In Lasanta, T. y Vide, J. (Coord.). La Investigación Geográfica en España (1990-2012) (pp. 389-400). Madrid: Asociación de Geógrafos Españoles/Instituto Pirenaico de Ecología.

Corbera, J. (2013). La Unió europea, un mosaic lingüístic. Palma: Edicions Documenta Balear/Edicions de la Universitat de les Illes Balears.

Corrêa, R. L. A. (1995). Espaço: Um Conceito-Chave da Geografia. In I. E. Castro, P.C. Gomes \& R. L. A. Corêa (Eds.), Geografia: Conceito e Temas (pp. 15-47). Rio de Janeiro: Editora Bertrand. Traducción al castellano en http://pdfhumanidades.com/sites/default/files/apuntes/Lobato\%20Corr\%C3\%AAa\%20\%281 995\%29\%20\%28en\%20espa\%C3\%B1ol\%29.pdf

Domingo, A. (2014). Catalunya al mirall de la immigració. Demografia i identitat nacional. Barcelona: L'Avenç.

Domingo, A. (2014). Catalunya al mirall de la immigració. Demografia i identitat nacional. Barcelona: L'Avenç.

Farinós, J. (Coord.) (2002). Geografia Regional d'Espanya. Una nova geografia per a la planificació i el deenvolupament regional. Valencia: Universidad de Valencia.

Farinós, J., Ojeda, J. F., \& Trillo, J. M. (Eds.) (2019). España: Geografías para un Estado posmoderno. Madrid/Barcelona: AGE/Geocrítica. Retrieved from https://www.agegeografia.es/site/espana-geografias-para-un-estado-posmoderno/

Font, J. (2013). La encrucijada catalana. In J. Gómez, R. C. Lois \& O. Nel.lo (Eds.), Repensar el Estado. Crisis económica, conflictos territoriales e identidades políticas en España (pp. 33-40). Santiago de Compostela: Universidade de Santiago de Compostela.

Furió, A. (2015). Las Españas medievales. In J. Romero \& A. Furió, Historia de las Españas. Una aproximación crítica (pp. 77-145). Valencica: Tirant Humandidades.

Fuster, J. (1962). Nosaltres el valencians. Barcelona: Edicions 62.

Gagnon, A. (2001). The Moral Foundations of Asymmetrical Federalism: a Normative Exploration of the case of Quebec and Canada. In A. Gagnon \& J. Tully (Eds.), Multinational Democracie. Cambridge: CUP.

García, J. (2002). Provincias, regiones y comunidades autónomas. La formación del mapa político de España. Madrid: Temas del Senado. 
García Fernández, J. (2000). La región y los cambios regionales en España. Investigaciones Geográficas, 24, $5-15$.

Retrieved from https://www.investigacionesgeograficas.com/article/view/2000-n24-la-region-y-loscambios-regionales-en-espana

García, J. Ma, \& Soleto, J. A. (1999). La España de las Autonomías. Madrid: Editorial Síntesis.

Gil, A., \& Gómez, J. (Coords.) (2001). Geografía de España. Barcelona: Editorial Ariel.

Gómez, J. (2013). Crisis catalana ¿crisis de estado de la autonomías? In J. Gómez, R. C. Lois, O. Nel.lo (Eds.), Repensar el Estado. Crisis económica, conflictos territoriales e identidades políticas en España (pp. 19-32). Santiago de Compostela: Universidade de Santiago de Compostela.

Gómez, J. (2018). Fifty years of Regional Geography in Spain: a University Spanish school and epoch-defining textbook. Boletín de la Asociación de Geógrafos Españoles, 79, 2744, 1-38. Retrieved from http://dx.doi.org/10.21138/bage.2744

Gómez, J. (2019). La idea de España (y de Cataluña) en Vicens Vives. De la Geopolítica a la Geohistoria: In J. Farinós, J. F. Ojeda \& J. Trillo (Eds.), Geografías para un Estado posmoderno (pp. 23-44). Madrid/Barcelona: AGE/Geocrítica. Retrieved from http://www.ub.edu/geocrit/estadoposmoderno.pdf

Gómez, J., Lois, R. C., \& Nel.lo, O. (Eds.). (2013). Repensar el Estado. Crisis económica, conflictos territoriales e identidades políticas en España. Santiago de Compostela: Universidade de Santiago de Compostela.

Guia, J. (1986). És molt senzill: digueu-li Catalunya. Centre i perifèria en la nació catalana. Barcelona: El Llamp.

Lefebvre, H. (1976). Espacio y política; el derecho a la ciudad, II. Barcelona: Ediciones Península. Lois, R. (2013). Recursos económico-financieros y equidad territorial en España. In J. Gómez, R. C. Lois, O. Nel.lo (Eds.), Repensar el Estado. Crisis económica, conflictos territoriales e identidades políticas en España (pp. 63-75). Santiago de Compostela: Universidade de Santiago de Compostela.

Lois, R. (2019). Territorio y territorios: reflexiones acerca de la variedad de los límites y las fronteras geográficas: In J. Farinós, J. F. Ojeda \& J. Trillo (Eds.), Geografías para un Estado posmoderno (pp. 209-218). Madrid/Barcelona:

AGE/Geocrítica. http://www.ub.edu/geocrit/estadoposmoderno.pdf 
Máiz, R. (2006). Federalismo plurinacional: una teoría política normativa. Revista d'Estudis Autonòmics i Federals. 43-85.

Margall, P. (2001, February 27). Madrid se va. El País. Retrieved from https://elpais.com/diario/2001/02/27/opinion/983228408_850215.html

Martínez, A. (1997). Romanticismo y nacionalismo. In A. de Blas (Dir.), Enciclopedia del nacionalismo (pp. 470-472). Madrid: Editorial Tecnos.

Mata, R. (2013). Reflexiones en torno a una reforma federal del estado autonómico desde una geografía regional de las Españas. In J. Gómez, R. C. Lois, O. Nel.lo (Eds.), Repensar el Estado. Crisis económica, conflictos territoriales e identidades políticas en España (pp. 147-160). Santiago de Compostela: Universidade de Santiago de Compostela.

Melià, J. (1967). Els mallorquins. Palma: Daédalus.

Melià, J. (1977). La nació dels mallorquins. Bareclona: Editorial Selecta.

Molinas, C. (2012, March 4). España, capital Madrid. Revista Cinco Días. Retrieved from https://elpais.com/economia/2012/03/02/actualidad/1330712282_179577.html

Moll, F. de B. (1962). Un home de combat: Mossèn Alcover. Palma: Editorial Moll.

Moll, F., \& Alcover, A. (1921). Mapa dels actuals dominis de la llengua catalana: ab indicació dels principals dialectes qui la formen y de les localitats estudiades lexicològicament per a la formació del Diccionar. In Institut Cartogràfic i Geològic de Catalunya. Cartoteca Digital. Retrieved

from http://cartotecadigital.icc.cat/cdm/singleitem/collection/catalunya/id/1153/rec/3

Nel.lo, O. (2013). La crisis catalana: orígenes y alternativas. In J. Gómez, R. C. Lois, O. Nel.lo (Eds.), Repensar el Estado. Crisis económica, conflictos territoriales e identidades políticas en España (pp. 41-54). Santiago de Compostela: Universidade de Santiago de Compostela.

Nel.lo, O., \& Gomà, A. (2018). Geographies of discontent: urban segregation, political attitudes and electoral behaviour in Catalonia. City, Territory and Architecture, 5(23), Retrieved from https://doi.org/10.1186/s40410-018-0099-z

Nogué, J. (1993). La dimensió territorial del nacionalisme. Treballs de la Societat Catalana de Geografia, 35, 193-201. Retrieved from https://publicacions.iec.cat/repository/pdf/00000074/00000024.pdf 
Olcina, J. (2013). Un encaje cultural y lingüístico complejo. In J. Gómez, R. C. Lois, O. Nel.lo (Eds.), Repensar el Estado. Crisis económica, conflictos territoriales e identidades políticas en España (pp. 115-126). Santiago de Compostela: Universidade de Santiago de Compostela.

Ortega, N. (2016). Geografía, Historia, Nación. Sobre las relaciones entre las condiciones geográficas y los hechos históricos y nacionales de España. In J. Olcina \& A. Rico (Coord.), Libro jubilar en homenaje al profesor Antonio Gil Olcina (pp. 707-724). Alicante: Instituto Interuniversitario de Geografía/Universidad de Alicante.

Plaza, J. I. (2013a). Las publicaciones de los geógrafos españoles en los congresos nacionales. In T. Lasanta \& J. Vide (Coord.). La Investigación Geográfica en España (1990-2012) (pp. 279296). Madrid: Asociación de Geógrafos Españoles/Instituto Pirenaico de Ecología.

Plaza, J. I. (2013b). Reorganización territorial y movimientos soberanistas en el marco europeo. In J. Gómez, R. C. Lois, O. Nel.lo (Eds.), Repensar el Estado. Crisis económica, conflictos territoriales e identidades políticas en España (pp. 161-168). Santiago de Compostela: Universidade de Santiago de Compostela.

Plaza, J. I. (2016). Algunas observaciones sobre los factores y los cambios en que se ha apoyado la evolución de la geografía regional de España. In J. Olcina \& A. Rico (Coord.), Libro jubilar en homenaje al profesor Antonio Gil Olcina. (pp. 1163-1178). Alicante: Instituto Interuniversitario de Geografía/Universidad de Alicante.

Rodríguez, F., \& Plaza, I. (2001). El difícil reto de seguir avanzandol (Presentación del número 32). Boletín de la Asociación de Geógrafos Españoles, 32, 5-11. Retrieved from https://www.age-geografia.es/ojs/index.php/bage/article/view/399

Romero, J. (2009). Geopolítica y gobierno del territorio en España. Valencia: Tirant lo Blanch.

Romero, J., \& Boira, J. V. (2017). El contexto geopolítico. In J. Romero (Coord.), Geografía Humana de España. Curso de introducción. (pp. 57-156) Valencia: Universidad de Valencia.

Ruíz, E. (1991). Euskal Herria, la tierra de la lengua vasca. Boletín de la Asociación de Geógrafos Españoles, 13, 5-19. Retrieved from https://dialnet.unirioja.es/ejemplar/120494

Sampol, P. (2018). El procés català amb ulls mallorquins. Palma: Lleonard Muntaner Editor.

Sánchez, R., \& Puente, A. (2017, December 28). Las elecciones del voto 'rufián': así creció el independentismo en el cinturón obrero de Barcelona. eldiario.es Retrieved from https://www.eldiario.es/politica/revancha-rufianes-independentismo-cinturon- 
Simón, A. (1997). Inmigración y nacionalismo catalán. In A. de Blas (Dir.), Enciclopedia del nacionalismo (pp. 246-248). Madrid: Editorial Tecnos.

Smith, A. D. (1976). Las teorías del nacionalismo. Barcelona: Ediciones Península.

Taylor, P. J. (1990). El Concepte de regió històrica i la regionalització d'Europa. Treballs de la Societat Catalana de Geografia, 21, 89-102.

Taylor, P. J., \& Flint, C. (2002). Geografía políitica. Economía mundo, Estado-nación y localidad. Mdrid: Trama Editorial.

Vicens, J. (1954). Notícia de Catalunya. Barcelona: Destino.

Vilar, P. (1964 [1960]). Catalunya dins l'Espanya Moderna. Recerques sobre els fonaments econòmics de els estructures nacionals. I, Introducció al medi natural. II, El marc històric. III, Les transformacions agràries del segle XVIII català. Barcelona: Edicions 62.

Zoido, F. (2013). El estado federal, un camino a recorrer. In J. Gómez, R. C. Lois, O. Nel.lo (Eds.), Repensar el Estado. Crisis económica, conflictos territoriales e identidades políticas en España (pp. 141-146). Santiago de Compostela: Universidade de Santiago de Compostela.

Zoido, F. (2019). Notas a propósito del "modelo territorial español" y propuesta sobre competencia estatal en ordenación del territorio y paisaje ante una posible revisión de la Constitución de 1978. In J. Farinós, J., J. F. Ojeda \& J. Trillo (Eds.), Geografías para un Estado posmoderno (pp. 101-104). Madrid/Barcelona: AGE/Geocrítica. Retrieved from http://www.ub.edu/geocrit/estadoposmoderno.pdf 